Disponível em:

http://editora.unoesc.edu.br/index.php/race

Race, Joaçaba, v. 14, n. 3, p. 1205-1268, set./dez. 2015

\title{
ANÁLISE DA INFLUÊNCIA DO PRIVATE EQUITY E DO VENTURE CAPITAL NO RISCO DAS AÇÕES DAS EMPRESAS QUE REALIZARAM IPO COMO FORMA DE DESINVESTIMENTO
}

\section{Influence Analysis of Private Equity and Venture Capital in Enterprise Risk Shares that held IPO as Divestment form}

Júlio Pereira de Araújo E-mail: juliop.araujo@gmail.com Mestre e doutorando em Administração pela Universidade Federal de Pernambuco.

Marcos Roberto Gois de Oliveira

E-mail:mrgois@hotmail.com

Doutor em Economia pela Universidade Federal de Pernambuco; Mestre em Administração pela Universidade Federal de Pernambuco; Professor associado da

Universidade Federal de Pernambuco.

Endereço para contato: Avenida dos economistas, Cidade Universitária, 50670-

902, Recife, Pernambuco, Brasil.

Artigo recebido em 23 de dezembro de 2014. Aceito em 30 de julho de 2015. 
Resumo

Neste artigo teve-se por objetivo comparar o risco das empresas que foram investidas por gestores de private equity e venture capital $(P E / V C)$ em relação às que não receberam esse tipo de investimento. A base de dados utilizada foi os preços e os retornos diários das ações das empresas que realizaram IPO no período de fevereiro/2006 a novembro/2010. Na análise verificaram-se aspectos de volatilidade dos preços das ações (normalidade, presença de raízes unitárias, autocorrelação serial dos erros e suporte aos efeitos heterocedásticos), e a metodologia utilizada foi o Value at Risk (VaR) com Simulação de Monte Carlo. Analisaram-se os VaRs individuais das empresas por ano de realização do IPO (2006 a 2010) e no período total. Cada $\mathrm{VaR}$ individual foi calculado considerando-se o melhor entre três modelos de volatilidade: desvio padrão, volatilidade com modelo GARCH mais parcimonioso e o melhor modelo GARCH encontrado pela metodologia Akaike. Os resultados da análise da volatilidade mostraram principalmente que a maioria das empresas apresenta suporte aos efeitos heterocedásticos. Em relação aos resultados do $\mathrm{VaR}$, tanto no período total quanto na análise por ano do IPO, o grupo de empresas que recebeu investimentos de $P E / V C$ apresentou maiores valores de $V a R$ em relação ao grupo sem $P E / V C$. Assim, pode-se concluir que o grupo de empresas com investimento de $P E / V C$ possui maior nível de risco em relação ao conjunto das empresas sem ele.

Palavras-chave: Private Equity. Venture Capital. Value at Risk.

\section{Influence Analysis of Private Equity and Venture Capital in Enterprise Risk Shares that held IPO as Divestment form}

\section{Abstract}

In this article we aimed to compare the risk of companies that have been invested by managers of private equity and venture capital (PE/VC) in relation to the ones that did not receive this kind of investment. The database used was the prices and daily stock returns of companies that performed IPO from February/2006 to November/2010. In the analysis, it was found aspects of volatility of stock prices (normal, presence of unit roots, serial autocorrelation of errors and support to heterocedastic effects) and the methodology used was the Value at Risk (VaR) with Monte Carlo Simulation. We analyzed the individual of VaR's companies per year of IPO (2006-2010) and total period. Each individual VaR was calculated based on the best of three models of volatility: standard deviation, volatility with more parsimonious GARCH model and the best GARCH model found by Akaike methodology. The results of the analysis of volatility showed mainly that most enterprises have support to heterocedastic effects. Regarding the results of $\mathrm{VaR}$, both in total period and in the analysis per year of the IPO, the group of companies that received PE/VC investments showed higher VaR values compared to those without PE/VC. Thus, we can conclude that the group of companies with PE/VC investment has a higher level of risk in relation to the companies without.

Keywords: Private Equity. Venture Capital. Value at Risk. 


\section{INTRODUÇÃO}

Os fundos de $P E / V C$ têm a função de investir em empresas com alto potencial de retorno. Eles adquirem parte do capital da companhia, ajudam a implantar novas políticas de gestão e de governança corporativa e, após alguns anos, liquidam as participações adquiridas (desinvestimento), com a expectativa de retorno aos investidores dos recursos. Além disso, fornecem uma alternativa viável ao financiamento tradicional, obtido por meio de empréstimos bancários. As empresas que recebem financiamento de $P E / V C$ geralmente fornecem ao mercado serviços e produtos inovadores, além de inovar nos processos produtivos e gerenciais e nas suas estratégias de marketing (RIBEIRO; TIRONI, 2007).

Os investimentos em $P E / V C$ são caracterizados no mercado e em pesquisas científicas como de alto retorno para as partes envolvidas, mas que carregam consigo, em contraposição, um elevado risco. Isso porque, ao investirem em empresas inovadoras, com desempenho incerto de curto e longo prazos, tanto os gestores quanto os investidores de $P E / V C$ se deparam com um elevado risco em relação a outros tipos de investimento. Para compensar o alto risco, esperam obter elevados retornos em longo prazo, em relação à média do desempenho do mercado acionário.

O desempenho das empresas que receberam investimentos em $P E / V C$ é observado a partir da ocorrência do desinvestimento por parte da organização gestora de PE/VC. Uma das formas de desinvestimento é o Initial Public Offering (IPO), nome atribuído à abertura de capital de uma organização no mercado de ações. Ele representa o momento em que a empresa investida começa a atuar de forma mais independente no mercado e a partir do qual começa a ser percebida a influência da organização gestora de $P E / V C$ sobre ela. Das formas de desinvestimento, o IPO é geralmente a mais bem-sucedida (SIQUEIRA; CARVALHO; NETTO, 2011; SCHWIENBACHER, 2008), além disso, o IPO foi a forma de saída mais utilizada pelas empresas investidas por $P E / V C$ no Brasil em 2013, representando $72 \%$ delas (ABVCAP, 2014).

Apesar de as estratégias usadas pelos gestores de $P E / V C$ na estruturação e administração dos investimentos serem conhecidas, pouco se sabe a respeito da influência delas sobre o seu sucesso. Isso se deve à falta de modelos teóricos, de dados sistemáticos sobre os processos de investimento adotados por gestores individuais e de indicadores do seu sucesso (ausência de dados públicos sobre taxas de retornos dos investimentos) (SIQUEIRA; CARVALHO; NETTO, 2011). 
No que diz respeito ao risco nessa atividade, ele foi abordado por Herger (2012) do ponto de vista dos investidores que estão apostando em fundos de private equity. Porém, o autor, além de analisar fundos e não empresas que receberam investimentos de $P E / V C$, considerou o risco com foco na análise da diversificação. Assim, carece-se de um estudo que analise o risco das empresas individuais que foram investidas por organizações gestoras de $P E / V C$.

No presente artigo, pretende-se abordar a variável risco na atividade de PE/ $V C$, a partir do comportamento dos retornos das ações das empresas que utilizaram IPO como forma de desinvestimento, comparando os valores de Value at Risk (VaR) das empresas que receberam com as que não receberam esse tipo de investimento.

\section{REFERENCIAL TEÓRICO}

O investimento em $P E / V C$ é caracterizado no mercado por possuir um elevado risco. Os tipos de risco mais citados são a assimetria de informações e a falta de liquidez. A assimetria de informações é uma consequência relacionada ao problema principal agente. Segundo Pindyck (2002), a assimetria de informação ocorre quando o agente, em determinada transação, detém alguma informação relevante que a outra parte não possui. Ou seja, as duas partes possuem informações diferentes sobre uma transação. Para Sahlman (1990), existe um alto grau inevitável de assimetria de informação entre os gestores de $P E / V C$, que desempenham um papel ativo nas empresas do portfólio, e os investidores, que não podem monitorar as perspectivas de cada investimento individual tão de perto.

A falta de liquidez em curto prazo é um dos fatores de risco a serem considerados pelos investidores de private equity. Segundo Ferrari e Minardi (2010), os investidores comprometem determinada quantia de capital quando o colocam em investimentos de $P E / V C$, considerando que somente terão liquidez e retorno após o encerramento do fundo. Dada a falta de liquidez desses investimentos, poucos são os investidores que conseguem casar seus prazos com os prazos desses fundos (CRESCIULO; MINARDI, 2012). Segundo Ramalho, Furtado e Lara (2011), dadas as características de baixa liquidez, elevado risco e alta expectativa de retorno, os veículos de $P E / V C$ são especialmente atrativos para investidores com elevado nível de riqueza e horizontes longos de investimento, como pessoas físicas abastadas, fundos de pensão, seguradoras, etc. 
Neste trabalho, o risco foi mensurado por meio do Value at Risk (VaR), baseando-se nos preços e nos retornos diários das ações das empresas analisadas. Segundo Jorion (1997), o Value at Risk representa um método de mensuração de risco de mercado que utiliza técnicas estatísticas, buscando medir a pior perda esperada de carteira, fundo ou instituição ao longo de um período de tempo, sob condições normais de mercado e dentro de determinado nível de confiança.

São várias as técnicas para se calcular o VaR de uma carteira ou de um ativo individual. Segundo Wiener (1999), todas as técnicas seguem a seguinte sequência:

a) seleção dos parâmetros básicos (horizonte de tempo, grau de confiança e tempo de mensuração);

b) seleção dos fatores relevantes do mercado;

c) acompanhamento do risco;

d) cálculo do VaR.

Segundo Saliby e Araújo (2001), existem três principais metodologias para o cálculo do VaR: métodos analíticos, que utilizam métodos estatísticos padronizados para calcular as variações no valor do portfólio atual, necessitando, para isso, considerar várias premissas para os fatores de mercado; método histórico, no qual se verificam as variações ocorridas nos fatores de mercado em certo período histórico e aplicam-se essas variações no portfólio atual, considerando-se o horizonte de tempo escolhido; e métodos por Simulação de Monte Carlo, nos quais se definem as distribuições e seus respectivos parâmetros para as variações dos fatores de mercado e a correlação existente entre esses fatores e, em seguida, simulam-se várias observações das possíveis variações dos fatores de mercado, verificando seus impactos no valor do portfólio atual.

Um dos métodos analíticos de grande relevância no âmbito do VaR é o método Delta-Normal, o que é baseado na hipótese de que os retornos são normalmente distribuídos. Assim, para o cálculo do VaR de apenas um ativo em uma carteira, tem-se (JORION, 1997):

$$
\mathrm{VaR}=\mathrm{W}_{0} \cdot \boldsymbol{\sigma} \cdot \boldsymbol{\alpha} \cdot \sqrt{ } \Delta \mathrm{t}
$$


onde $\mathrm{W}_{0}$ é o valor aplicado; $\boldsymbol{\sigma}$ é a volatilidade; $\boldsymbol{\alpha}$ representa o fator de segurança retirado da distribuição teórica assumida (em geral a distribuição normal padrão) referente ao nível de confiança desejado; e $\Delta$ t é o tempo de aplicação.

A estimativa da volatilidade utilizada na Equação 1 é, geralmente, retirada dos dados históricos. Uma forma simples seria considerar a volatilidade como o desvio padrão dos retornos do portfólio. Porém, dessa forma, todas as observações possuiriam o mesmo peso, independentemente se ocorreram na véspera do cálculo ou no início do período analisado. Além disso, segundo Jorion (1997), a maioria dos ativos financeiros possui caldas grossas em suas distribuições. Já Bollerslev (1986) descobriu que a maioria dos retornos das variáveis financeiras tende a apresentar assimetria e a ser leptocúrtica, não apresentando, assim, características de normalidade.

O método de simulação histórica consiste em utilizar as variações passadas dos fatores de risco para gerar cenários, simular a função de distribuição de probabilidade para os retornos da carteira e estimar o VaR. Ele simplifica drasticamente a abordagem de cálculo do $V a R$, pois não faz nenhuma suposição sobre a distribuição dos retornos (MANGANELLI; ENGLE, 2003), porém, também é alvo de algumas críticas. Ele assume que o passado representa bem o futuro imediato, contudo, o risco varia significativamente com o tempo. Além disso, o método não trata, de forma adequada, situações com volatilidade temporariamente elevada (JORION, 1997).

Assim, com o objetivo de modelar a volatilidade das séries com as características dos retornos, além de outras, surgiram os modelos heterocedásticos. O primeiro modelo desenvolvido foi apresentado por Engle (1982) e denominase Modelo Autorregressivo de Heterocedasticidade Condicional (ARCH). Um processo $\mathrm{X}_{\mathrm{t}}$ é considerado ARCH de ordem q se:

$$
\begin{aligned}
& X_{t}=\sigma_{t} \varepsilon_{t}, \text { onde } \sigma_{t}^{2}=\alpha_{0}+\alpha_{1} X_{t-1}^{2}+\ldots+\alpha_{q} X_{t-q}^{2} \\
& X_{t}=\sigma_{t} \varepsilon_{t}, \text { onde } \sigma_{t}^{2}=\alpha_{0}+\alpha_{1} X_{t-1}^{2}+\ldots+\alpha_{q} X_{t-q}^{2}
\end{aligned}
$$

onde $\sigma_{t} \sigma_{t}$ é uma sequência não negativa de variáveis aleatórias, $\varepsilon_{t}$ $\varepsilon_{t}$ é uma sequência de variáveis aleatórias independentes e identicamente distribuídas, conhecidas pela sigla "iid" de valor médio nulo e variância unitária. Já os parâmetros $\alpha_{i} \alpha_{i}$ devem satisfazer um conjunto de condições para garantir que 
a variância não condicionada seja infinita: $\alpha_{0}>0$ e $\alpha_{i} \geq 0, i=1,2, \ldots, q$ $\alpha_{0}>0$ e $\alpha_{i} \geq 0, i=1,2, \ldots, q$ (ENGLE, 1982).

Porém, o modelo possui a desvantagem de exigir muitos parâmetros para descrever adequadamente o comportamento da volatilidade (TSAY, 2005). Dessa forma, Bollerslev (1986) propôs um modelo que seria uma ampliação do ARCH e que possui como características ser mais parcimonioso e flexível, denominado Modelo Autorregressivo de Heterocedasticidade Condicional Generalizado (GARCH).

Segundo Oliveira e Carmona (2008), entre os principais modelos de estimação de volatilidade, os que contemplam a volatilidade condicional ganham destaque. É o caso dos modelos da família GARCH. Além de reproduzirem algumas das principais características das séries financeiras, eles representam modelos parcimoniosos. O modelo padrão é assim apresentado:

$$
\begin{aligned}
& y_{t}=\beta^{\prime} x_{t}+E_{t} y_{t}=\beta^{\prime} x_{t}+E_{t} \\
& \sigma_{t}^{2}=\alpha_{0}+\sum_{i=1}^{p} \delta_{i} \sigma_{t-i}^{2}+\sum_{i=j}^{q} \alpha_{i} \varepsilon_{t-j}^{2} \\
& \sigma_{t}^{2}=\alpha_{0}+\sum_{i=1}^{p} \delta_{i} \sigma_{t-i}^{2}+\sum_{i=j}^{q} \alpha_{i} \varepsilon_{t-j}^{2}
\end{aligned}
$$

A Equação 3 é a da média, onde $y_{t} y_{t}$ representa a taxa de retorno da ação; $x_{t} x_{t}$ é uma matriz de regressores e $E_{t} E_{t}$ o termo de erro. A Equação 4 indica a função de variância condicional e é função de três fatores: variância média $\alpha_{0} \alpha_{0}$, informação sobre a volatilidade passada mensurada pelo termo defasado quadrado $E_{t-j}^{2} E_{t-j}^{2}\left(\right.$ termo ARCH) e variância dos períodos anteriores $\sigma_{t-i}^{2} \sigma_{t-i}^{2}$ (termo GARCH) (OLIVEIRA; CARMONA, 2008).

Por fim, torna-se importante ressaltar que os estimadores de volatilidade devem ser construídos considerando-se as regularidades empíricas das séries financeiras. Taylor (1986) apresenta os fatos estilizados de tais séries, entre elas que as distribuições apresentam ausência de normalidade com excesso de curtoses e assimetria negativa. Além disso, possuem características de heterocedasticidade.

O Bank for International Settlements (BIS) afirma que deve haver medidas verificáveis do desempenho dos sistemas de gestão de risco das instituições 
financeiras e recomenda que um teste de validação seja incorporado aos modelos internos de gestão do risco. Um dos testes de validação do modelo para o cálculo do VaR denomina-se teste de Kupiec. Trata-se de um método estatístico que utiliza exatamente a frequência de vezes em que o $V a R$ é extrapolado. Considerando uma amostra de resultados para um dado ativo, geram-se intervalos de valores aceitáveis para a frequência de extrapolações, dado um nível de confiança estipulado. Com base nesses valores, pode-se definir uma regra de decisão para aceitar ou rejeitar o modelo testado. Ressalta-se que a escolha do nível de significância do teste não tem nenhuma relação com aquele definido para o cálculo do VaR (GOULART, 2009).

Outro teste que verifica a eficácia do modelo de $\mathrm{VaR}$ foi desenvolvido por Lopez (1996) e se baseia em uma função de perda. A ideia foi criar essa função para incorporar os critérios julgados importantes pelos órgãos de regulamentação. O modelo que minimizasse essa função seria considerado o melhor.

Muitas vezes as técnicas analíticas não podem ser utilizadas e os resultados da simulação histórica não são satisfatórios. É necessária, então, a utilização de métodos numéricos de integração. Uma das técnicas possíveis é o método de Simulação de Monte Carlo (MSMC) (OLIVEIRA; TAVORA JUNIOR, 2006).

Segundo Saliby e Araújo (2001), os métodos por Simulação de Monte Carlo são considerados os mais robustos e os mais poderosos para o cálculo do Value at Risk, pois podem contemplar grande variedade de riscos financeiros, e todas as variáveis do modelo podem ser tratadas como probabilísticas, caso isso venha a ser de interesse. Além disso, segundo Jorion (1997), incorporam os riscos não lineares, os de volatilidade e os de modelo, podendo incorporar a variação temporal da volatilidade, caudas grossas e cenários extremos.

O método consiste na simulação do comportamento dos fatores de risco e dos preços dos ativos pela simulação do movimento dos preços. A partir disso, o método constrói $\mathrm{N}$ possíveis valores da carteira para determinada data futura e o VaR pode ser estimado diretamente a partir da distribuição dos valores simulados dessa carteira. Assim, a metodologia resume-se, em suma, na geração aleatória de cenários para os fatores de risco, cenários que devem ser condizentes com a matriz de variância-covariância histórica. Ou seja, a essência desse método está na especificação dos processos aleatórios e na geração de números aleatórios (OLIVEIRA; TAVORA JUNIOR, 2006).

Para Jorion (1997), a mais importante etapa da simulação consiste em escolher um modelo estocástico para o comportamento dos preços. Um modelo habitualmente utilizado é o movimento browniano geométrico (MBG), que 
pressupõe que as inovações no preço do ativo não são autocorrelacionadas e que pequenas oscilações nos preços podem ser descritas por:

$$
\frac{d S_{t}}{S_{t}} \frac{d S_{t}}{S_{t}}=\mu d t+\sigma d z_{\mathrm{t}}
$$

Na Equação 5 o primeiro componente representa o fator previsibilidade. $\mu$ é a medida da taxa média de aumento do preço do ativo. O rendimento desse ativo pode ser comparado ao rendimento de um ativo livre de risco e é dado por $\mu \mathrm{dt}$. A segunda hipótese sugere que o modelo tenha um elemento relacionado com a chegada de novas informações, que está representada pelo termo $\boldsymbol{\sigma d z t}$, em que $\boldsymbol{\sigma}$ é a volatilidade e a medida dzt é uma variável aleatória oriunda de uma distribuição normal.

A volatilidade pode ser calculada pelos modelos da família GARCH. Já os valores aleatórios podem ser gerados por qualquer software, pois necessitam de algorítmos determinísticos. Utilizando o Lemma de Itô, pode-se obter uma solução para a Equação 5. Supondo que o preço inicial do ativo $\mathrm{S}(\mathrm{t} 0)=\mathrm{S} 0>0$ no tempo $\mathrm{t}$ $=\mathrm{t} 0 \geq 0$, e admitindo que em $\mathrm{t} 0=0$ o valor de $\mathrm{z} 0=0$, a solução da Equação será dada por:

$$
S(t)=S_{0} \exp \left[\left(\mu-\frac{11}{22} \boldsymbol{\sigma}^{2}\right) t+\boldsymbol{\sigma} d z_{t}\right]
$$

Para a simulação de uma trajetória de preços para $S(t)$, inicia-se com $S_{0}$ e gera-se uma sequência de $\in$ para $t=1,2,3, \ldots, n$. Posteriormente, calcula-se $S(1)$, $S(2), \ldots S(n)$.

Neste trabalho adotaram-se duas soluções para a trajetória de preços: a primeira é a Equação 7, em que $\mu$ é substituído por $r$, que representa a taxa de juros livre de risco supondo retorno risk-neural, obtendo-se a precificação de Euler de ativos para a volatilidade constante; e a segunda é uma extensão da primeira, denominada solução de Milstein para a volatilidade constante (Equação 8).

$$
S t_{+\Delta t}=S t\left[1+r \Delta t+\sigma_{t} \Delta z_{t}\right]
$$




$$
S t_{+\Delta \mathrm{t}}=S_{t}\left[1+r \Delta t+\sigma_{\mathrm{t}} \Delta z_{\mathrm{t}}+\frac{11}{22} \sigma_{\mathrm{t}}^{2}\left(\left(\Delta z_{\mathrm{t}}\right)^{2}-\Delta t\right)\right]
$$

Neste artigo substituiu-se $\mu$ por valores diferentes de $r$. Assim, além das soluções anteriores utilizando $r$ como médias dos modelos, estimou-se ainda o VaR com o $\mu$ obtido por estimação da média obtida diretamente da equação do GARCH (Equação 3) ou por meio de volatilidade tradicional.

No Brasil há poucos estudos que abordem a variável risco de forma quantitativa nos investimentos de $P E / V C$. Um desses trabalhos foi o de Herger (2012), o qual considerou o ponto de vista dos investidores de fundos de $P E / V C$ e estudou o risco sob a ótica da diversificação. O autor analisou uma amostra de 2.699 fundos, todos com foco de investimento na Europa ou EUA e cujo início ocorreu entre 1983 e 2003. Analisou-se o risco na atividade de private equity por meio de uma metodologia similar ao VaR histórico, criada pelo autor e denominada iCaR (Capital Investido em Risco). Com essa medida de risco baseada no valor investido em fundos de private equity e com o uso de simulações de Monte Carlo, permitiuse concluir que uma combinação de (i) estratégias de diversificação com (ii) uma carteira de private equity diversificada globalmente em diferentes tipos de fundos resulta em um iCaR zero, com $99 \%$ de confiança.

O objetivo neste artigo foi comparar o risco das empresas que foram investidas por gestores de PE/VC e que realizaram IPO no período de 09 de fevereiro de 2006 a 03 de novembro de 2010 em relação às empresas que não receberam esse tipo de investimento e que abriram capital no mesmo período.

\section{PROCEDIMENTOS METODOLÓGICOS}

Com o objetivo de detectar se existe diferença estatisticamente significativa no risco das empresas, foram inicialmente coletados os preços diários de fechamento das ações das empresas que realizaram IPO no período de 09 de fevereiro de 2006 a 03 de novembro de 2010. Os dados foram coletados do portal Infomoney e as informações a respeito de quais empresas abriram capital no período foram retiradas do portal do BMF \& Bovespa. Posteriormente, essas empresas foram divididas em dois subgrupos: as que receberam investimentos de PE/VC (possuíam ao menos um fundo de PE/VC na data do IPO) e as que não receberam esse tipo de investimento. A identificação da presença ou não de fundos de PE/VC nas empresas foi feita por 
meio da observação dos prospectos destas no site da Comissão de Valores Mobiliários (CVM).

Foram considerados na amostra apenas os IPOs, retirando-se, assim os Follow-on. No período considerado, houve 109 IPOs, dos quais uma empresa saiu da bolsa antes do tempo considerado na análise; uma passou por reestruturação societária; 10 foram incorporadas por outras empresas que já constavam na base de dados; cinco apresentaram valores de retorno muito irregulares, com vários períodos sem negociação; e 12 não apresentaram dados de retorno suficientes para todo o período considerado. Ao final, restaram 80 operações no período de análise, as quais podem ser visualizadas na Tabela 1 , por ano de realização e pela presença ou não de fundos de $P E / V C$ :

Tabela 1 - Resumo das operações de IPO

\begin{tabular}{ccc}
\hline Ano & Com PE/VC & Sem PE/VC \\
\hline 2006 & 7 & 11 \\
2007 & 11 & 35 \\
2008 & 1 & 2 \\
2009 & 2 & 2 \\
2010 & 5 & 4 \\
Total & 26 & 54 \\
Fonte: os autores. & &
\end{tabular}

A primeira etapa da metodologia foi a análise dos aspectos de volatilidade das empresas para serem inseridas nos respectivos modelos de VaR. A segunda etapa foi a realização dos cálculos de VaR e a comparação entre os dois grupos de empresas (com e sem PE/VC). Os valores foram gerados por meio de códigos programados na plataforma do Matlab 8.0.

Antes de serem calculados os Value at Risk (VaR) de todas as empresas, fezse necessária uma análise prévia dos comportamentos das volatilidades inerentes aos retornos diários das empresas. Tal análise foi feita com os preços de fechamento das ações individuais, sendo as datas iniciais as de realização dos IPOs das empresas e a data final de 13 de dezembro de 2013.

Foram verificados os seguintes aspectos de volatilidade: 
a) normalidade: utilização do teste de Jarque-Bera para verificar a existência de normalidade nos retornos diários das ações. O resultado do teste influi no modelo de cálculo do $\mathrm{VaR}$.

b) raiz Unitária: utilização do teste de Dickey-Fuller para a avaliação da presença de raiz unitária para os retornos. A ausência de raízes unitárias caracteriza que a série é estacionária. A principal implicativa econômica é que não havendo raízes unitárias os choques não terão efeitos permanentes (GREENE, 2000).

c) autocorrelação serial: no caso das séries serem estacionárias, deve-se avaliar a presença de autocorrelações, ou correlação serial dos erros entre períodos de tempo. Tal análise é um primeiro indício da presença ou não de um efeito $\mathrm{ARCH}$ na série. A avaliação quantitativa utilizada foi o teste de Ljung-Box-Pierce Q-teste.

d) suporte aos Efeitos Heterocedásticos: análise dos aspectos de heterocedasticidade. Foi utilizado o teste de Engle para analisar o suporte aos modelos heterocedásticos de desenho da variância.

e) melhor Modelo de Volatilidade: seleção dos modelos autorregressivos heterocedásticos mais eficientes. Para tal, foi utilizada a metodologia de Akaike (AIC).

Foram realizados os cálculos dos VaRs individuais de todas as empresas, considerando os mesmos períodos, a mesma fonte de dados e o mesmo software da análise de volatilidade. Utilizou-se para cada empresa três cálculos de VaR com Simulação de Monte Carlo: VaR 1: Método tradicional (uso de desvio padrão para a volatilidade); VaR 2: Método $\operatorname{GARCH}(0,0)(1,1)$ (mais parcimonioso); VaR 3: Método GARCH com volatilidade própria (determinada pela metodologia AIC de cada empresa).

Os valores calculados dos VaRs foram considerados com as seguintes variáveis:

a) número de violações: utilizado como parâmetro para a análise da eficiência do VaR.

b) percentual de violações: número de violações em percentual. Para este trabalho, conforme definem os órgãos reguladores, os valores superiores a $10 \%$ foram considerados má especificação do modelo e 
foram rejeitados os valores do VaR para efeito das análises comparativas entre as empresas.

c) teste de Kupiec: A para aprovado e $\mathrm{R}$ para reprovado, em razão dos valores de percentual de violações.

d) Perda de Lopez: outro teste para verificar a eficiência do VaR, alternativo ao teste de Kupiec.

e) VaR médio: valor do VaR médio por empresa.

f) VaR máximo: valor do VaR máximo por empresa.

g) VaR mínimo: valor do VaR mínimo por empresa.

Posteriormente, foram selecionados os melhores VaRs de cada empresa (entre os aprovados pelo teste de Kupiec), baseando-se, em primeiro lugar, no menor percentual de violações, e em segundo lugar, no menor valor da Perda de Lopez. Esses valores foram os considerados para a análise temporal do risco. Verificaram-se os valores de $V a R$ por ano de realização do IPO e no período completo da amostra. Essa análise ocorreu presumindo-se que os fatores macroeconômicos temporais podem ter interferência nos respectivos valores de VaR. Exceção ocorreu no ano 2008, pois no grupo de empresas com PE/VC, apenas uma realizou IPO nesse ano, porém, todos os seus três cálculos de VaR foram reprovados pelos testes utilizados, inviabilizando a análise. Os valores foram analisados por ordem decrescente de $\mathrm{VaR}$ médio, máximo e mínimo.

\section{RESULTADOS}

Em relação às características de volatilidade, previamente verificadas para o cálculo do $V a R$, não foram encontradas diferenças significativas entre as empresas que receberam investimentos em $P E / V C$ e as que não receberam. A Tabela 2 resume as características.

Tabela 2 - Resumo das características de volatilidade

\begin{tabular}{crrrr}
\hline Empresa & Normalidade & $\begin{array}{c}\text { Raiz } \\
\text { Unitária }\end{array}$ & $\begin{array}{c}\text { Autocorrelação } \\
\text { Serial Retorno }\end{array}$ & $\begin{array}{c}\text { Suporte Efeitos } \\
\text { Heterocedásticos }\end{array}$ \\
\hline Com PE/VC & $0 \%$ & $0 \%$ & $54 \%$ & $92 \%$ \\
Sem PE/VC & $0 \%$ & $0 \%$ & $65 \%$ & $96 \%$ \\
\hline Fonte: os autores. & & & &
\end{tabular}

Fonte: os autores. 
Em relação à avaliação da presença de características de normalidade das distribuições, todas as empresas apresentaram não ter características de normalidade. Tal fato confirma os fatos estilizados abordados por Taylor (1986) de que as séries financeiras possuem ausência de normalidade em suas distribuições. Assim, permitiu-se desconsiderar os modelos de VaR Delta-Normal, dado que consideram as séries distribuições normais, e considerar modelos mais adequados às séries.

Sobre a avaliação da presença de raiz unitária nas séries, todas as empresas também têm ausência de raízes unitárias, o que caracteriza serem estacionárias. Com isso, confirma-se que, por não haver raízes unitárias, os choques não terão efeitos permanentes. Com isso, não houve a necessidade de realizar diferenciações, o que é normal para as séries financeiras, já que o próprio cálculo do retorno é uma diferenciação.

Como as séries são estacionárias, é necessário avaliar a presença de autocorrelações ou correlação serial dos erros entre períodos de tempo. A análise mostrou que das 26 empresas com PE/VC, 14 (54\%) apresentam autocorrelação serial nos retornos. Já das 54 empresas sem PE/VC, 35 (65\%) apresentaram autocorrelação. Dessa forma, pode-se perceber que a maioria das empresas em ambos os grupos possui indícios de suporte aos efeitos ARCH, porém, em maior quantidade nas empresas que não receberam investimentos em $P E / V C$.

Para confirmar a presença de efeitos heterocedásticos nas séries, analisou-se os resultados do teste de Engle. Das 26 empresas com PE/VC, 24 (92\%) apresentaram suporte aos efeitos heterocedásticos, enquanto que das 54 empresas sem $P E / V C, 52$ (96\%) confirmaram tal comportamento. Dessa forma, pode-se decidir pelo uso de volatilidades com modelos GARCH para serem inseridos nos cálculos dos VaRs com Simulação de Monte Carlo.

Por fim, analisaram-se os melhores modelos de volatilidade pelo critério de Akaike. Não foram observadas diferenças significativas em ambos os grupos. Tais valores também serviram de parâmetro para a formulação dos modelos de $V a R$, bem como para seus respectivos cálculos, ao serem inseridos nos respectivos modelos GARCH.

\subsection{VALUE AT RISK (VAR)}

No Apêndice A estão os valores dos VaRs de todas as empresas da amostra. Nas primeiras colunas estão as características de cada empresa em termos de ano de 
realização do IPO e se possuem ou não investimento em PE/VC. Posteriormente, encontra-se a identificação dos valores dos VaRs de cada empresa: o VaR 1, com volatilidade tradicional (desvio padrão); o $\operatorname{VaR} 2$, com volatilidade GARCH $(0,0)$ $(1,1)$, considerado o mais parcimonioso; e o VaR 3, com volatilidade GARCH determinada pela metodologia de Akaike. A ausência de alguns valores no VaR 3 é decorrente de o GARCH individual ter a ordem de um modelo mais parcimonioso $(0,0)(1,1)$.

Logo após estão os números e os percentuais de violações de cada modelo, os valores do teste de Perda de Lopez e o indício de aprovação (A) ou não (R) no teste de Kupiec. Essas colunas demonstram a eficácia dos modelos de VaR construídos. Os valores do percentual de violações (que advém da Perda de Lopez) superiores a $10 \%$ foram considerados reprovados pelo teste de Kupiec. Observa-se no Apêndice A que, no geral, os modelos se adequaram bem aos dados, ocorrendo aprovação na maioria das empresas. Por fim, estão os valores de VaR médio, máximo e mínimo por empresa e por metodologia de VaR.

Nos demais Apêndices (B a Q) estão os melhores VaRs de todas as empresas deste estudo e os valores por ano de IPO realizado. Exceção ocorreu no ano 2008, pois a única empresa que possui PE/VC que abriu capital nesse ano teve os três valores de $\mathrm{VaR}$ reprovados pelo teste de Kupiec, inviabilizando a comparação. Os valores foram retirados dentre os melhores modelos de VaR do Apêndice A e conforme critérios detalhados na seção 3. Cada grupo foi classificado em ordem decrescente de VaR médio, máximo e mínimo, e os seus resultados e análises estão demonstrados nas subseções seguintes. Visando enfatizar melhor a diferença entre os valores de $\mathrm{VaR}$ das empresas que receberam investimento de $\mathrm{PE} / \mathrm{VC}$ e as que não receberam, foram analisadas para cada período as estatísticas descritivas (média e mediana) dos valores de VaR por grupo.

\subsubsection{VaR completo}

Nos Apêndices B, C e D estão localizados os valores dos VaRs para toda a amostra em todo o período da análise, o que totaliza 75 empresas com valores de VaR. Destas, 25 possuem PE/VC e 50 não possuem. O Apêndice B está classificado por ordem decrescente de $V a R$ médio. Por meio da sua análise é possível observar que $60 \%$ dos 10 maiores VaRs médios são de empresas com PE/VC, apesar dessas últimas estarem em menor quantidade na pesquisa, enfatizando mais a diferença. 
Observando-se o valor relativo, percebe-se que $24 \%$ das empresas com PE/VC situam-se entre os 10 maiores VaRs. Considerando que o universo é de 75 empresas, é possível notar uma diferença significante entre os dois grupos. Observando a parte inferior do quadro, verifica-se que $90 \%$ dos 10 menores VaRs são de empresas sem $P E / V C$, o que confirma o comportamento de valores maiores de VaR para empresas com $P E / V C$ e menores para as demais empresas.

Analisando-se as estatísticas descritivas dos VaRs na Tabela 3, a diferença entre os dois grupos de empresas é ainda mais nítida. As empresas com PE/VC apresentaram médias e medianas superiores às empresas sem $P E / V C$ e à amostra total.

Tabela 3 - Estatística descritiva do VaR médio completo

\begin{tabular}{lcr}
\hline & Média & \multicolumn{1}{c}{ Mediana } \\
\hline Amostra total & $-0,03316$ & $-0,02838$ \\
Com PE/VC & $-0,03859$ & $-0,03104$ \\
Sem PE/VC & $-0,03044$ & $-0,02827$ \\
\hline Fonte: os autores. & &
\end{tabular}

No Apêndice C os valores de VaR estão classificados em ordem decrescente de VaR máximo. Nele, observa-se que $80 \%$ dos 10 maiores VaRs máximos são de empresas com $P E / V C$. Pelo valor relativo, tem-se que $32 \%$ das empresas com PE/ $V C$ estão entre os 10 maiores VaRs. Na faixa inferior, verifica-se que $80 \%$ dos 10 menores VaRs são de empresas sem $P E / V C$. A Tabela 4 confirma a diferença de comportamentos, mostrando que as empresas com $P E / V C$ apresentaram valores de média e mediana superiores às empresas sem $P E / V C$ e à amostra total.

Tabela 4 - Estatística descritiva do VaR máximo completo

\begin{tabular}{lcr}
\hline & Média & \multicolumn{1}{c}{ Mediana } \\
\hline Amostra total & $-0,05774$ & $-0,03896$ \\
Com PE/VC & $-0,08526$ & $-0,04660$ \\
Sem PE/VC & $-0,04398$ & $-0,03711$ \\
\hline
\end{tabular}

Fonte: os autores. 
Por fim, o apêndice D mostra os valores classificados por ordem decrescente de VaR mínimo. Nele, é possível observar que 70\% dos 10 menores VaRs mínimos são de empresas sem $P E / V C$. Mais uma vez as estatísticas descritivas dos grupos confirmam diferenças entre eles, com as empresas com $P E / V C$ apresentando valores maiores. Os números estão demonstrados na Tabela 5.

Dessa forma, pode-se perceber diferenças de VaR entre os grupos de empresas com e sem investimento em $P E / V C$, pois, observa-se o primeiro possui maiores valores em relação ao segundo, possuindo, dessa forma, um maior nível de risco ao considerar-se toda a amostra e todo o período analisado neste trabalho.

Tabela 5 - Estatística descritiva do VaR mínimo completo

\begin{tabular}{lcc}
\hline & Média & \multicolumn{1}{c}{ Mediana } \\
\hline Amostra total & $-0,02562$ & $-0,02392$ \\
Com PE/VC & $-0,02819$ & $-0,02494$ \\
Sem PE/VC & $-0,02434$ & $-0,02254$ \\
\hline Fonte: os autores. & &
\end{tabular}

As demais análises foram feitas por ano de realização do $I P O$ com o objetivo de verificar comportamentos temporais e retirar possíveis efeitos do ambiente macroeconômico na análise. Seus resultados aparecem nas subseções seguintes.

\subsubsection{VaR 2006}

Nos Apêndices E, F e G estão os VaRs das empresas que realizaram IPO em 2006 divididas por ordem de classificação de VaR médio, máximo e mínimo, respectivamente. Esse grupo possui 18 empresas, das quais sete possuem $P E / V C$ e 11 não possuem. No caso do Apêndice $\mathrm{E}$, a análise visual e individual dos valores não permitiu chegar a uma conclusão que diferenciasse os dois grupos. Observa-se que dos cinco primeiros VaRs, três são de empresas sem $P E / V C$ e dois com $P E /$ $V C$. Já na parte inferior dos dados, dos cinco menores VaRs médios, quatro são de empresas sem $P E / V C$. Porém, apesar dessas diferenças, o número de empresas sem $P E / V C$ nessa amostra é superior, o que não permite tirar conclusões pertinentes.

Porém, quando são analisadas as estatísticas descritivas dos dados, observase nitidamente a diferença entre os dois grupos, apresentando as empresas com PE/ 
$V C$ maiores valores de média e mediana que o grupo sem $P E / V C$ e que a amostra total. Os dados estão dispostos na Tabela 6.

Tabela 6 - Estatística descritiva do VaR médio 2006

\begin{tabular}{lcc}
\hline & Média & Mediana \\
\hline Amostra total & $-0,03894$ & $-0,03070$ \\
Com PE/VC & $-0,04291$ & $-0,03298$ \\
Sem PE/VC & $-0,03642$ & $-0,02728$ \\
\hline Fonte: os autores. & &
\end{tabular}

Pelo Apêndice F pode-se observar visualmente que apenas um valor maior de VaR máximo se destacou perante os demais, sendo ele pertencente a uma empresa com PE/VC. A Tabela 7 mostra mais uma vez que as empresas com PE/VC possuem valores médios e medianos superiores, agora se considerando os VaRs máximos.

Tabela 7 - Estatística descritiva do VaR máximo 2006

\begin{tabular}{lcc}
\hline & Média & \multicolumn{1}{c}{ Mediana } \\
\hline Amostra total & $-0,08611$ & $-0,04042$ \\
Com PE/VC & $-0,12922$ & $-0,04140$ \\
Sem PE/VC & $-0,05869$ & $-0,04018$ \\
\hline Fonte: os autores
\end{tabular}

Por fim, o Apêndice $G$ apresenta os valores das empresas que realizaram IPO em 2006 por ordem de VaR mínimo. Observa-se que as cinco empresas com menores valores de $V a R$ mínimo não possuem $P E / V C$, o que vai ao encontro dos comportamentos anteriores. As estatísticas descritivas que aparecem na Tabela 8 confirmam tal diferença: novamente o grupo das empresas com $P E / V C$ apresentou maiores valores em relação ao grupo sem $P E / V C$ e em relação à amostra total, dessa vez, considerando-se VaRs mínimos. 
Tabela 8 - Estatística descritiva do VaR mínimo 2006

\begin{tabular}{lcc}
\hline & \multicolumn{1}{c}{ Média } & \multicolumn{1}{l}{ Mediana } \\
\hline Amostra total & $-0,02725$ & $-0,02471$ \\
Com PE/VC & $-0,02877$ & $-0,02651$ \\
Sem PE/VC & $-0,02629$ & $-0,02290$ \\
\hline Fonte: os autores. & &
\end{tabular}

Assim, as análises de todos os critérios de classificação dos VaRs das empresas que abriram capital em 2006 permitiram chegar à mesma conclusão da análise do VaR completo, de que as empresas que receberam investimentos em $P E / V C$ possuem nível de risco maior, em sua maioria, por possuírem valores mais elevados de VaR em relação às demais empresas.

\subsubsection{VaR 2007}

Nos Apêndices H, I e J estão os valores de VaR das empresas que abriram capital no ano 2007 por ordem de classificação de VaR médio, máximo e mínimo, respectivamente. Nesse ano, 43 empresas realizaram IPO, das quais 11 possuíam investimento em $P E / V C$ e 32 não possuíam. Inicialmente, observa-se no Apêndice H que nos 10 maiores VaRs médios estão 45\% das empresas com $P E / V C$ do grupo. Ou seja, das 11 empresas com PE/VC, cinco estão na faixa dos 10 maiores VaRs entre os 43 do período. Além disso, o primeiro colocado se distancia do segundo em uma diferença maior que as demais diferenças de valores consecutivos e pertence a uma empresa sem PE/VC. Por fim, 90\% dos 10 menores VaRs médios são de empresas sem $P E / V C$. A Tabela 9 possui os valores das estatísticas descritivas por grupo e confirma as diferenças de valores de $V a R$ entre as empresas com e sem $P E / V C$, pois observa-se que as primeiras apresentam valores maiores que as segundas e que a amostra total.

Tabela 9 - Estatística descritiva do VaR médio 2007

\begin{tabular}{lcc}
\hline & Média & \multicolumn{2}{c}{ Mediana } \\
\hline Amostra total & $-0,03163$ & $-0,02920$ \\
Com PE/VC & $-0,03858$ & $-0,03450$ \\
Sem PE/VC & $-0,02924$ & $-0,02867$ \\
\hline
\end{tabular}

Fonte: os autores. 
Observando-se a classificação por VaR máximo (Apêndice I), vê-se que nos 10 maiores valores estão 64\% das empresas com $P E / V C$ do grupo. Ou seja, das 11 empresas com $P E / V C$, sete estão na faixa dos 10 maiores valores. Ainda, dos 10 maiores VaRs, 70\% são de empresas com $P E / V C$, apesar de serem minoria no grupo, o que enfatiza mais a diferença. Por fim, 90\% dos 10 menores valores são de empresas que não receberam investimentos de $P E / V C$. Observando-se por outro viés, é possível ver que os cinco maiores VaRs são de empresas com $P E / V C$ e os cinco menores, de empresas sem esse tipo de investimento. Essas diferenças em termos de risco foram confirmadas com as análises de média e mediana das empresas com e sem $P E / V C$; mais uma vez as empresas que foram investidas por esses tipos de gestores apresentaram valores superiores às que não receberam tal investimento e à amostra total. Os valores estão detalhados na Tabela 10.

Tabela 10 - Estatística descritiva do VaR máximo 2007

\begin{tabular}{lcc}
\hline & Média & \multicolumn{1}{c}{ Mediana } \\
\hline Amostra total & $-0,05255$ & $-0,03943$ \\
Com PE/VC & $-0,08651$ & $-0,07413$ \\
Sem PE/VC & $-0,04087$ & $-0,03676$ \\
\hline
\end{tabular}

Fonte: os autores.

A análise visual dos valores classificados por ordem de VaR mínimo (Apêndice J) não permitiu chegar a conclusões pertinentes de diferenças entre os dois grupos de empresas, pois ambos estão bem distribuídos. Porém, quando se observam os valores das estatísticas descritivas na Tabela 11, verifica-se outra vez que as empresas com $\mathrm{PE} / \mathrm{VC}$ apresentaram valores superiores de $\mathrm{VaR}$ em relação às empresas sem PE/VC e à amostra total.

Tabela 11 - Estatística descritiva do VaR mínimo 2007

\begin{tabular}{lrr}
\hline & \multicolumn{1}{c}{ Média } & \multicolumn{1}{c}{ Mediana } \\
\hline Amostra total & $-0,02482$ & $-0,02425$ \\
Com PE/VC & $-0,02669$ & $-0,02434$ \\
Sem PE/VC & $-0,02418$ & $-0,02339$ \\
\hline Fonte: os autores. & &
\end{tabular}


Assim, o comportamento observado no ano 2007 assemelha-se às conclusões tiradas na análise do $\mathrm{VaR}$ completo e do ano 2006, de que as empresas que receberam investimentos em $P E / V C$ possuem, em geral, maiores valores de $V a R$, ou seja, maior nível de risco.

\subsubsection{VaR 2009}

Os Apêndices L, M e $\mathrm{N}$ apresentam os VaRs das empresas que realizaram IPO em 2009. Nesse ano, apenas quatro empresas abriram capital, duas com PE/ $V C$ e duas sem esse investimento. Em primeiro lugar, o Apêndice L classificou as empresas por ordem de $V a R$ médio. Nele, é possível observar claramente que os maiores valores são de empresas com $P E / V C$ e os menores, sem $P E / V C$. Tal diferença é confirmada na análise das estatísticas descritivas da Tabela 12.

Tabela 12 - Estatística descritiva do VaR médio 2009

\begin{tabular}{lrr}
\hline & Média & \multicolumn{1}{c}{ Mediana } \\
\hline Amostra total & $-0,02497$ & $-0,02463$ \\
Com PE/VC & $-0,02663$ & $-0,02663$ \\
Sem PE/VC & $-0,02331$ & $-0,02331$ \\
\hline Fonte: os autores. & &
\end{tabular}

No Apêndice M (por ordem de VaR máximo), observa-se que o maior $V a R$ máximo se destaca com uma diferença maior em relação às outras subsequentes, e essa empresa possui investimento em PE/VC. Em razão disso, os valores das estatísticas descritivas demonstraram também valores maiores de $V a R$ das empresas com PE/VC sobre os outros dois grupos. Tais valores encontram-se na Tabela 13.

Tabela 13 - Estatística descritiva do VaR máximo 2009

\begin{tabular}{lcc}
\hline & Média & \multicolumn{1}{l}{ Mediana } \\
\hline Amostra total & $-0,03121$ & $-0,02707$ \\
Com PE/VC & $-0,03678$ & $-0,03678$ \\
Sem PE/VC & $-0,02564$ & $-0,02564$ \\
\hline
\end{tabular}

Fonte: os autores. 
Por fim, a análise visual do $\operatorname{VaR}$ mínimo (Apêndice $\mathrm{N}$ ) não permitiu tirar conclusões sobre diferenças de valores entre as empresas com e sem $P E / V C$. Na Tabela 14 encontram-se as estatísticas descritivas desses dois grupos e da amostra total.

Tabela 14 - Estatística descritiva do VaR mínimo 2009

\begin{tabular}{lcc}
\hline & Média & \multicolumn{1}{c}{ Mediana } \\
\hline Amostra total & $-0,01820$ & $-0,01910$ \\
Com PE/VC & $-0,01729$ & $-0,01729$ \\
Sem PE/VC & $-0,01910$ & $-0,01910$ \\
\hline Fonte: os autores &
\end{tabular}

Nela se pode perceber que houve diferença de comportamento em relação às análises anteriores, com as empresas com $\mathrm{PE} / \mathrm{VC}$ apresentando valores menores de $\mathrm{VaR}$ em relação às empresas sem $P E / V C$ e à amostra total.

Dessa forma, a amostra das empresas com PE/VC que abriram capital em 2009 apresentou maiores níveis de risco quando se consideraram os VaRs médio e máximo, mostrando as mesmas conclusões das análises anteriores. Porém, quando foi analisado o VaR mínimo, esse ano se mostrou diferente em relação aos períodos anteriores, pois as empresas com $P E / V C$ apresentaram valores menores de média e mediana.

\subsubsection{VaR 2010}

Por fim, nos Apêndices $\mathrm{O}, \mathrm{P}$ e Q estão os valores de $\mathrm{VaR}$ das empresas que abriram capital em 2010 por ordem decrescente de VaR médio, máximo e mínimo. Nesse ano, nove empresas realizaram IPO, das quais cinco possuem $P E / V C$ e quatro não possuem, sendo consideradas dessas últimas apenas três, pois uma não possui valor. Inicialmente, o Apêndice $\mathrm{O}$ mostra que das três empresas sem PE/ $V C$ do grupo, duas estão situadas nos menores VaRs médios. Além disso, o maior VaR médio possui uma diferença considerável em relação aos demais e pertence a uma empresa com $P E / V C$. Os valores de média e mediana por grupo de análise confirmam que o grupo de empresas que recebeu investimentos em $P E / V C$ possui maiores valores de $V a R$ em relação aos demais grupos. Os valores estão inseridos na Tabela 15. 
Tabela 15 - Estatística descritiva do VaR médio 2010

\begin{tabular}{lll}
\hline & Média & \multicolumn{1}{c}{ Mediana } \\
\hline Amostra total & $-0,03273$ & $-0,02663$ \\
Com PE/VC & $-0,03738$ & $-0,02697$ \\
Sem PE/VC & $-0,02499$ & $-0,02239$ \\
\hline
\end{tabular}

Fonte: os autores.

No Apêndice P, vê-se que o maior VaR máximo possui uma diferença superior em relação às empresas subsequentes, destacando-se no grupo. Esse valor pertence a uma empresa com PE/VC. As estatísticas descritivas (Tabela 16) apresentaram pela primeira vez comportamentos diferentes de média e mediana. As empresas com PE/VC apresentaram média maior, porém, mediana menor em relação aos grupos de empresas sem PE/VC e da amostra total. Essa diferença é compreensível, considerando que valores muito grandes ou muito pequenos em relação aos outros do grupo enviesam o valor da média, tornando a mediana uma medida mais confiável. Dessa forma, analisando-se do ponto de vista do grupo, pode-se considerar que o grupo de empresas com PE/VC apresentou, dessa vez, valor inferior do ponto de vista do VaR máximo.

\begin{tabular}{lcc} 
Tabela 16 - Estatística descritiva do VaR máximo 2010 & \multicolumn{2}{c}{ Mediana } \\
\hline Média & $-0,03778$ & $-0,02964$ \\
Com PE/VC & $-0,04038$ & $-0,02854$ \\
Sem PE/VC & $-0,03345$ & $-0,03621$
\end{tabular}

Fonte: os autores.

Por fim, o Apêndice $Q$ se assemelha ao comportamento do $V a R$ médio, já que das três empresas sem PE/VC do grupo, duas ficaram nos menores VaRs mínimos. Também houve diferença de destaque do maior valor, dessa vez sem interferir na conclusão da análise das estatísticas descritivas, que mostraram ser superiores para as empresas com $P E / V C$ sobre as demais. A Tabela 17 detalha os valores. 
Tabela 17 - Estatística descritiva do VaR mínimo 2010

\begin{tabular}{lcr}
\hline & Média & \multicolumn{1}{c}{ Mediana } \\
\hline Amostra total & $-0,02989$ & $-0,02495$ \\
Com PE/VC & $-0,03506$ & $-0,02496$ \\
Sem PE/VC & $-0,02127$ & $-0,02059$ \\
\hline Fonte: os autores & &
\end{tabular}

Fonte: os autores.

Portanto, esta seção permitiu concluir que, de forma geral, o grupo de empresas que recebeu investimentos em $P E / V C$ apresentou valores superiores de $V a R$, ou maior nível de risco em relação às empresas que não receberam esse tipo de investimento.

\section{CONCLUSÃO}

Procurou-se, com este estudo, observar se o investimento de PE/VC realizado nas empresas resultaria em um nível de risco diferente das empresas que não receberam esse tipo de investimento, considerando-se a metodologia do VaR com Simulação de Monte Carlo e aspectos de volatilidade das séries.

$\mathrm{Na}$ análise não foram encontradas características diferentes de volatilidade nos preços de fechamento diário das ações das empresas com investimento em $\mathrm{PE} / \mathrm{VC}$ em relação às demais ao serem verificados aspectos como normalidade das distribuições, presença de raiz unitária, presença de autocorrelações dos erros e suporte aos efeitos heterocedásticos. Mesmo assim, pode-se perceber que a maioria das empresas da amostra apresenta suporte aos efeitos heterocedásticos, o que permitiu o uso da volatilidade GARCH.

No caso da análise do VaR, os resultados mostraram que as amostras das empresas que foram investidas por organizações gestoras de PE/VC apresentaram valores maiores em relação às que não foram investidas, considerando-se os VaRs médio, máximo e mínimo individuais com o uso de Simulação de Monte Carlo e um dos três tipos de volatilidade: desvio padrão, modelos GARCH mais parcimoniosos $((0,0)(1,1))$ e modelos GARCH identificados como melhores pela metodologia Akaike (AIC), sendo escolhidos os valores que apresentassem menores percentuais de violação e considerando os Testes de Kupiec e Perda de Lopez. Essa conclusão foi 
possível em razão de que apenas o VaR mínimo de 2009 e o VaR máximo de 2010 apresentaram valores menores para as empresas com PE/VC.

Assim, neste trabalho, concluiu-se que as empresas que receberam investimentos de gestores de $P E / V C$ apresentam maiores níveis de risco em relação às empresas que não foram investidas por eles, considerando-se a metodologia do $\mathrm{VaR}$. Assim, pode-se comprovar de forma quantitativa o que a literatura afirma a respeito do risco das empresas que recebem investimento de $P E / V C$, sendo maior principalmente pelo fato de elas apresentarem maior assimetria de informações e falta de liquidez em curto prazo.

Por possuírem risco mais elevado, os investidores de $P E / V C$ devem exigir maiores retornos médios para o investimento, visando compensar a alta volatilidade dos retornos e os altos valores de $V a R$ aos quais estão expostos. Essa recompensa vem em médio e longo prazos no caso desse tipo de investimento e depende das características do empreendimento, do comportamento do mercado e dos perfis do investidor, da empresa gestora de $P E / V C$ e do empreendedor, além de outras variáveis internas.

\section{REFERÊNCIAS}

ASSOCIAÇÃO BRASILEIRA DE PRIVATE EQUITY E VENTURE CAPITAL. Disponível em: <http://www.abvcap.com.br>. Acesso em: 02 maio 2014.

BOLLERSLEV, T. Generalized autoregressive conditional heteroskedasticity. Journal of Econometrics, v. 31, p. 307-327, 1986.

CRESCIULO, F. C.; MINARDI, A. M. A. F. Um Retrato da Indústria de Venture Capital Brasileira - Fundo Mútuo de Investimento em Empresas Emergentes. Insper Instituto de Ensino e Pesquisa, 2012.

ENGLE, R. F. Autoregressive conditional heteroscedasticity with estimates of variance of United Kingdom inflation. Econometrica, v. 50, i. 4, p. 987-1007, 1982.

FERRARI, G. L.; MINARDI, A. M. A. F. O desempenho de Ofertas Públicas Iniciais de Empresas Brasileiras Financiadas por Fundos de Private Equity. Insper Instituto de Ensino e Pesquisa, 2010.

GOULART, P. M. Avaliação da Metodologia Value At Risk Aplicada à Análise da Volatilidade de Títulos Públicos Federais Prefixados. Revista Gestão e Tecnologia, Pedro Leopoldo, v. 9, p. 1-11, 2009. 
GREENE, W. H. Econometric Analysis. 4. ed. New Jersey: Prentice Hall: Upper River, 2000.

HERGER, I. Qual é o risco real do Private Equity? Revista Fundos de Pensão, ano 31, p. 43-46, 2012.

JORION, P. Value at Risk: A nova fonte de referência para o controle do risco de Mercado. São Paulo: Bolsa de Mercadorias e Futuros, 1997.

LOPEZ, J. A. Regulatory Evaluation of Value at Risk Models. Mimeo, Research and Market Analysis Group, Federal Reserve Bank of New York, 1996.

MANGANELLI, S.; ENGLE, R. Value-at-Risk models in finance. Social Science Research Network, Rochester, Aug. 2003. Working Paper 75.

OLIVEIRA, M. R. G.; CARMONA, C. U. M. Value at risk dinâmico aplicado à taxa de câmbio de países latino-americanos: um estudo multiperíodo entre os modelos heterocedásticos e homocedástico. Revista de Administração Eletrônica, v. 1, 2008.

OLIVEIRA, M. R. G.; TAVORA JUNIOR, J. L. Value at risk dinâmico: um estudo comparativo entre os modelos heterocedásticos e a simulação de monte carlo. Revista Brasileira de Finanças, v. 4, p. 181-202, 2006.

PINDYCK, R. S.; RUBINFELD, D. L. Microeconomia. 5. ed. São Paulo: Prentice Hall, 2002.

RAMALHO, C.; FURTADO, C. V.; LARA, R. A Indústria de Private Equity e Venture Capital. $2^{\circ}$ censo brasileiro. Agência Brasileira de Desenvolvimento Industrial, Centro de Gestão e Estudos Estratégicos. Brasília, DF: Agência Brasileira de Desenvolvimento Industrial, 2011.

RIBEIRO, L. L.; TIRONI, L. F. Ativos Intangíveis: Avaliação e Mensuração no Contexto de Private Equity e Venture Capital. Ipea, Texto para Discussão, n. 1280, Brasília, DF, 2007.

SAHLMAN, W. A. The structure and governance of venture-capital organizations. Journal of Financial Economics, v. 27, p. 473-521, 1990.

SALIBY, E.; ARAÚJO, M. S. Cálculo do VaR através de Simulação de Monte Carlo: uma avaliação de uso de métodos amostrais mais eficientes. In: ENCONTRO ANUAL DA ANPAD, 25., 2001, São Paulo. Anais... São Paulo: ANPAD, 2001. 
SCHWIENBACHER, A. Innovation and Venture Capital Exits. The Economic Journal, v. 118, p. 1888-1916, 2008.

SIQUEIRA, E.; CARVALHO, A.; NETTO, H. Determinantes do sucesso dos investimentos de Private Equity e Venture Capital no Brasil. Revista brasileira de finanças, v. 9, p. 189-208, 2011.

TAYLOR, S. J. Modelling Financial Time Series. Chitester: John Wiley, 1986.

TSAY, R. Analysis of Financial Time Series. New Jersey: John Wiley and Sons, 2005.

WIENER, Z. Introduction to VaR (Value at Risk). Risk Management and Regulation in Banking. Boston: Kluwer Academic Publishers, 1999.

\section{COMO CITAR ESTE ARTIGO:}

ARAÚJO, Júlio Pereira de; OLIVEIRA, Marcos Roberto Gois de. Análise da — Influência do Private Equity e do Venture Capital no Risco das Ações das Empresas que Realizaram IPO como Forma de Desinvestimento. RACE, Revista de Administração, Contabilidade e Economia, Joaçaba: Ed. Unoesc, v. 14, n. 3 , p. 1205-1268, set./dez. 2015. Disponível em: < http://editora.unoesc.edu.br/index. php/race >. Acesso em: dia/mês/ano. Araújo, J. P. de, \& Oliveira, M. R. G. de (2015). Análise da Influência do Private
Equity e do Venture Capital no Risco das Ações das Empresas que Realizaram IPO como Forma de Desinvestimento. RACE, Revista de Administração, Contabilidade e Economia, 14(3), p. 1205-1268. Recuperado em dia/mês/ano, de http://editora. unoesc.edu.br/index.php/race 
APÊNDICE A - VAR POR EMPRESA

\begin{tabular}{|c|c|c|c|c|c|c|c|c|c|c|}
\hline Empresa & PE/VC & ANO IPO & $\begin{array}{c}\text { Metodo- } \\
\text { logia }\end{array}$ & $\begin{array}{c}\text { Número } \\
\text { de Viola- } \\
\text { ções }\end{array}$ & $\begin{array}{l}\text { Percentual } \\
\text { de Viola- } \\
\text { çóes }\end{array}$ & $\begin{array}{l}\text { Teste de } \\
\text { Kupiec }\end{array}$ & $\begin{array}{c}\text { Perda de } \\
\text { Lopez }\end{array}$ & VaR Médio & $\begin{array}{l}\text { VaR Máxi- } \\
\text { mo }\end{array}$ & $\begin{array}{c}\text { VaR Míni- } \\
\text { mo }\end{array}$ \\
\hline \multirow{3}{*}{ GFSA3 } & \multirow{3}{*}{ SIM } & \multirow{3}{*}{2006} & VaR 1 & 15 & 6 & A & 0,060017 & $-0,058635$ & $-0,062646$ & $-0,052173$ \\
\hline & & & VaR 2 & 18 & 7,2 & $\mathrm{~A}$ & 0,072022 & $-0,053574$ & $-0,080749$ & $-0,038423$ \\
\hline & & & VaR 3 & 19 & 7,6 & A & 0,076023 & $-0,053426$ & $-0,08000$ & $-0,038427$ \\
\hline \multirow{3}{*}{ TOTS3 } & \multirow{3}{*}{ SIM } & \multirow{3}{*}{2006} & VaR 1 & 17 & 6,8 & A & 0,068014 & $-0,026489$ & $-0,027743$ & $-0,024419$ \\
\hline & & & VaR 2 & 16 & 6,4 & $\mathrm{~A}$ & 0,064016 & $-0,026076$ & $-0,04140$ & $-0,022559$ \\
\hline & & & VaR 3 & - & - & - & - & - & - & - \\
\hline \multirow{3}{*}{ EQTL3 } & \multirow{3}{*}{ SIM } & \multirow{3}{*}{2006} & VaR 1 & 9 & 3,6 & A & 0,036005 & $-0,02600$ & $-0,028862$ & $-0,020157$ \\
\hline & & & VaR 2 & 10 & 4 & A & 0,040006 & $-0,023655$ & $-0,046649$ & $-0,014457$ \\
\hline & & & VaR 3 & 10 & 4 & A & 0,040006 & $-0,02350$ & $-0,044738$ & $-0,014606$ \\
\hline \multirow{3}{*}{ CARD3 } & \multirow{3}{*}{ SIM } & \multirow{3}{*}{2006} & VaR 1 & 15 & 6 & A & 0,060161 & $-0,032211$ & $-0,035846$ & $-0,025086$ \\
\hline & & & VaR 2 & 12 & 4,8 & A & 0,048161 & $-0,034409$ & $-0,06157$ & $-0,022072$ \\
\hline & & & VaR 3 & 17 & 6,8 & A & 0,068159 & $-0,031709$ & $-0,14589$ & $-0,014074$ \\
\hline \multirow{3}{*}{ LUPA3 } & \multirow{3}{*}{ SIM } & \multirow{3}{*}{2006} & VaR 1 & 26 & 10,4 & $\mathrm{R}$ & 0,10517 & $-0,066139$ & $-0,13309$ & $-0,04260$ \\
\hline & & & VaR 2 & 17 & 6,8 & A & 0,068061 & $-0,093826$ & $-0,64066$ & $-0,028664$ \\
\hline & & & $\mathrm{VaR} 3$ & 17 & 6,8 & A & 0,068108 & $-0,094159$ & $-0,64435$ & $-0,028859$ \\
\hline \multirow{3}{*}{ GPIV33 } & \multirow{3}{*}{ SIM } & \multirow{3}{*}{2006} & VaR 1 & 13 & 5.2 & $\mathrm{~A}$ & 0,052013 & $-0,03298$ & $-0,038957$ & $-0,02922$ \\
\hline & & & VaR 2 & 20 & 8 & A & 0,080017 & $-0,031276$ & $-0,061767$ & $-0,024477$ \\
\hline & & & VaR 3 & 20 & 8 & A & 0,080016 & $-0,031345$ & $-0,069493$ & $-0,021009$ \\
\hline \multirow{3}{*}{ ODPV3 } & \multirow{3}{*}{ SIM } & \multirow{3}{*}{2006} & VaR 1 & 16 & 6,4 & A & 0,06401 & $-0,028413$ & $-0,030433$ & $-0,02651$ \\
\hline & & & VaR 2 & 17 & 6,8 & A & 0,068013 & $-0,027252$ & $-0,04480$ & $-0,01290$ \\
\hline & & & $\mathrm{VaR} 3$ & 18 & 7,2 & $\mathrm{~A}$ & 0,072014 & $-0,026927$ & $-0,043024$ & $-0,01226$ \\
\hline
\end{tabular}




\begin{tabular}{|c|c|c|c|c|c|c|c|c|c|c|}
\hline Empresa & PE/VC & ANO IPO & $\begin{array}{c}\text { Metodo- } \\
\text { logia }\end{array}$ & $\begin{array}{l}\text { Número } \\
\text { de Viola- } \\
\text { çóes }\end{array}$ & $\begin{array}{c}\text { Percentual } \\
\text { de Viola- } \\
\text { ções }\end{array}$ & $\begin{array}{l}\text { Teste de } \\
\text { Kupiec }\end{array}$ & $\begin{array}{l}\text { Perda de } \\
\text { Lopez }\end{array}$ & VaR Médio & $\begin{array}{l}\text { VaR Máxi- } \\
\text { mo }\end{array}$ & $\begin{array}{c}\text { VaR Míni- } \\
\text { mo }\end{array}$ \\
\hline \multirow{3}{*}{ CSMG3 } & \multirow{3}{*}{ NÃO } & \multirow{3}{*}{2006} & VaR 1 & 17 & 6,8 & A & 0,068038 & $-0,027194$ & $-0,02920$ & $-0,024674$ \\
\hline & & & $\mathrm{VaR} 2$ & 16 & 6,4 & A & 0,064038 & $-0,027283$ & $-0,04100$ & $-0,019687$ \\
\hline & & & $\mathrm{VaR} 3$ & 19 & 7,6 & A & 0,076038 & $-0,026787$ & $-0,079063$ & $-0,018533$ \\
\hline \multirow{3}{*}{ VLID3 } & \multirow{3}{*}{ NÃO } & \multirow{3}{*}{2006} & VaR 1 & 17 & 6,8 & A & 0,068016 & $-0,025031$ & $-0,027755$ & $-0,02290$ \\
\hline & & & VaR 2 & 19 & 7,6 & A & 0,076018 & $-0,02526$ & $-0,059015$ & $-0,019419$ \\
\hline & & & VaR 3 & - & - & - & - & - & - & - \\
\hline \multirow{3}{*}{ MMXM3 } & \multirow{3}{*}{ NÃO } & \multirow{3}{*}{2006} & VaR 1 & 33 & 13,2 & $\mathrm{R}$ & 0,13232 & $-0,071474$ & $-0,097294$ & $-0,053661$ \\
\hline & & & $\mathrm{VaR} 2$ & 21 & 8,4 & A & 0,084174 & $-0,090361$ & $-0,26656$ & $-0,03493$ \\
\hline & & & VaR 3 & 27 & 10,8 & $\mathrm{R}$ & 0,10818 & $-0,088171$ & $-0,36238$ & $-0,035561$ \\
\hline \multirow{3}{*}{ MDIA3 } & \multirow{3}{*}{ NÃO } & \multirow{3}{*}{2006} & VaR 1 & - & - & - & - & - & - & - \\
\hline & & & VaR 2 & 11 & 4,4 & A & 0,04400 & $-0,020067$ & $-0,027719$ & $-0,01853$ \\
\hline & & & VaR 3 & 11 & 4,4 & A & 0,04400 & $-0,020041$ & $-0,026937$ & $-0,01857$ \\
\hline \multirow{3}{*}{ BISA3 } & \multirow{3}{*}{ NÃO } & \multirow{3}{*}{2006} & VaR 1 & 21 & 8,4 & A & 0,08403 & $-0,050721$ & $-0,053732$ & $-0,04832$ \\
\hline & & & $\mathrm{VaR} 2$ & 24 & 9,6 & A & 0,096033 & $-0,049365$ & $-0,069948$ & $-0,03604$ \\
\hline & & & VaR 3 & 23 & 9,2 & A & 0,092033 & $-0,049443$ & $-0,071153$ & $-0,03439$ \\
\hline \multirow{3}{*}{ PFRM3 } & \multirow{3}{*}{ NÃO } & \multirow{3}{*}{2006} & VaR 1 & 12 & 4,8 & A & 0,048072 & $-0,036657$ & $-0,04018$ & $-0,02824$ \\
\hline & & & $\mathrm{VaR} 2$ & 13 & 5,2 & A & 0,052066 & $-0,035759$ & $-0,13456$ & $-0,01703$ \\
\hline & & & VaR 3 & 13 & 5,2 & A & 0,052067 & $-0,034908$ & $-0,16024$ & $-0,01720$ \\
\hline \multirow{3}{*}{ TAEE11 } & \multirow{3}{*}{ NÃO } & \multirow{3}{*}{2006} & VaR 1 & 14 & 5,6 & A & 0,056017 & $-0,024364$ & $-0,029973$ & $-0,01908$ \\
\hline & & & VaR 2 & 19 & 7,6 & A & 0,07602 & $-0,02130$ & $-0,052144$ & $-0,01491$ \\
\hline & & & VaR 3 & - & - & - & - & - & - & - \\
\hline
\end{tabular}




\begin{tabular}{|c|c|c|c|c|c|c|c|c|c|c|}
\hline Empresa & PE/VC & ANO IPO & $\begin{array}{l}\text { Metodo- } \\
\text { logia }\end{array}$ & $\begin{array}{c}\text { Número } \\
\text { de Viola- } \\
\text { ções }\end{array}$ & $\begin{array}{l}\text { Percentual } \\
\text { de Viola- } \\
\text { ções }\end{array}$ & $\begin{array}{l}\text { Teste de } \\
\text { Kupiec }\end{array}$ & $\begin{array}{c}\text { Perda de } \\
\text { Lopez }\end{array}$ & VaR Médio & $\begin{array}{l}\text { VaR Máxi- } \\
\text { mo }\end{array}$ & $\begin{array}{l}\text { VaR Míni- } \\
\text { mo }\end{array}$ \\
\hline \multirow{3}{*}{ VAGR3 } & \multirow{3}{*}{ NÃO } & \multirow{3}{*}{2006} & VaR 1 & 12 & 4,8 & A & 0,04800 & $-0,037782$ & $-0,046292$ & $-0,03189$ \\
\hline & & & $\mathrm{VaR} 2$ & 12 & 4,8 & A & 0,048006 & $-0,035206$ & $-0,052619$ & $-0,02172$ \\
\hline & & & $\mathrm{VaR} 3$ & - & - & - & - & - & - & - \\
\hline \multirow{3}{*}{ POSI3 } & \multirow{3}{*}{ NÃO } & \multirow{3}{*}{2006} & $\mathrm{VaR} 1$ & 22 & 8,8 & A & 0,088056 & $-0,03670$ & $-0,040657$ & $-0,03436$ \\
\hline & & & $\mathrm{VaR} 2$ & 23 & 9,2 & A & 0,092059 & $-0,035648$ & $-0,13150$ & $-0,01961$ \\
\hline & & & VaR 3 & - & - & - & - & - & - & - \\
\hline \multirow{3}{*}{ LPSB3 } & \multirow{3}{*}{ NÃO } & \multirow{3}{*}{2006} & $\mathrm{VaR} 1$ & 31 & 12,4 & $\mathrm{R}$ & 0,12402 & $-0,026191$ & $-0,02901$ & $-0,02342$ \\
\hline & & & $\mathrm{VaR} 2$ & 23 & 9,2 & A & 0,092016 & $-0,026678$ & $-0,038826$ & $-0,01111$ \\
\hline & & & VaR 3 & 24 & 9,6 & $\mathrm{~A}$ & 0,096016 & $-0,026588$ & $-0,044093$ & $-0,01136$ \\
\hline \multirow{3}{*}{ DAGB33 } & \multirow{3}{*}{ NÃO } & \multirow{3}{*}{2006} & VaR 1 & - & - & - & - & - & - & - \\
\hline & & & $\mathrm{VaR} 2$ & 11 & 4,4 & A & 0,04400 & $-0,02502$ & $-0,032851$ & $-0,02012$ \\
\hline & & & $\mathrm{VaR} 3$ & - & - & - & - & - & - & - \\
\hline \multirow{3}{*}{ PDGR3 } & \multirow{3}{*}{ SIM } & \multirow{3}{*}{2007} & $\mathrm{VaR} 1$ & 17 & 6,8 & A & 0,068019 & $-0,050219$ & $-0,05447$ & $-0,04572$ \\
\hline & & & $\mathrm{VaR} 2$ & 19 & 7,6 & $\mathrm{~A}$ & 0,076026 & $-0,04813$ & $-0,07125$ & $-0,033023$ \\
\hline & & & VaR 3 & - & - & - & - & - & - & - \\
\hline \multirow{3}{*}{ EVEN3 } & \multirow{3}{*}{ SIM } & \multirow{3}{*}{2007} & VaR 1 & 13 & 5,2 & A & 0,05202 & $-0,032329$ & $-0,036007$ & $-0,029878$ \\
\hline & & & $\mathrm{VaR} 2$ & 12 & 4,8 & A & 0,048023 & $-0,031327$ & $-0,069086$ & $-0,024336$ \\
\hline & & & $\mathrm{VaR} 3$ & - & - & - & - & - & - & - \\
\hline \multirow{3}{*}{ BRML3 } & \multirow{3}{*}{ SIM } & \multirow{3}{*}{2007} & $\mathrm{VaR} 1$ & 22 & 8,8 & A & 0,088012 & $-0,027273$ & $-0,030314$ & $-0,02529$ \\
\hline & & & $\mathrm{VaR} 2$ & 25 & 10 & A & 0,10001 & $-0,026281$ & $-0,032016$ & $-0,02176$ \\
\hline & & & VaR 3 & 23 & 9,2 & A & 0,092014 & $-0,025934$ & $-0,033413$ & $-0,02139$ \\
\hline
\end{tabular}




\begin{tabular}{|c|c|c|c|c|c|c|c|c|c|c|}
\hline Empresa & PE/VC & ANO IPO & $\begin{array}{c}\text { Metodo- } \\
\text { logia }\end{array}$ & $\begin{array}{c}\text { Número } \\
\text { de Viola- } \\
\text { çóes }\end{array}$ & $\begin{array}{c}\text { Percentual } \\
\text { de Viola- } \\
\text { çóes }\end{array}$ & $\begin{array}{l}\text { Teste de } \\
\text { Kupiec }\end{array}$ & $\begin{array}{c}\text { Perda de } \\
\text { Lopez }\end{array}$ & VaR Médio & $\begin{array}{c}\text { VaR Máxi- } \\
\text { mo }\end{array}$ & $\begin{array}{c}\text { VaR Míni- } \\
\text { mo }\end{array}$ \\
\hline \multirow{3}{*}{ BEMA3 } & \multirow{3}{*}{ SIM } & \multirow{3}{*}{2007} & VaR 1 & 8 & 3,2 & A & 0,03201 & $-0,03108$ & $-0,033742$ & $-0,02538$ \\
\hline & & & VaR 2 & 6 & 2,4 & A & 0,024013 & $-0,031042$ & $-0,07860$ & $-0,01420$ \\
\hline & & & VaR 3 & 8 & 3,2 & A & 0,032013 & $-0,031032$ & $-0,078606$ & $-0,01414$ \\
\hline \multirow{3}{*}{ CREM3 } & \multirow{3}{*}{ SIM } & \multirow{3}{*}{2007} & VaR 1 & 16 & 6,4 & A & 0,064017 & $-0,026992$ & $-0,02863$ & $-0,02460$ \\
\hline & & & VaR 2 & 12 & 4,8 & A & 0,048018 & $-0,026471$ & $-0,07614$ & $-0,022605$ \\
\hline & & & VaR 3 & 14 & 5,6 & A & 0,056019 & $-0,025958$ & $-0,055461$ & $-0,02270$ \\
\hline \multirow{3}{*}{ VIVR3 } & \multirow{3}{*}{ SIM } & \multirow{3}{*}{2007} & $\mathrm{VaR} 1$ & 31 & 12,4 & $\mathrm{R}$ & 0,12423 & $-0,056271$ & $-0,081978$ & $-0,033184$ \\
\hline & & & VaR 2 & 17 & 6,8 & A & 0,06811 & $-0,077209$ & $-0,24017$ & $-0,038144$ \\
\hline & & & VaR 3 & 18 & 7,2 & $\mathrm{~A}$ & $-0,07210$ & $-0,079011$ & $-0,15654$ & $-0,038489$ \\
\hline \multirow{3}{*}{ MRVE3 } & \multirow{3}{*}{ SIM } & \multirow{3}{*}{2007} & VaR 1 & - & - & - & - & - & - & - \\
\hline & & & VaR 2 & 20 & 8 & A & 0,080017 & $-0,04570$ & $-0,08370$ & $-0,024245$ \\
\hline & & & $\operatorname{VaR} 3$ & - & - & - & - & - & - & - \\
\hline \multirow{3}{*}{ SGPS3 } & \multirow{3}{*}{ SIM } & \multirow{3}{*}{2007} & VaR 1 & 23 & 9,2 & $\mathrm{~A}$ & 0,092112 & $-0,04039$ & $-0,04360$ & $-0,036661$ \\
\hline & & & VaR 2 & 18 & 7,2 & A & 0,072112 & $-0,03995$ & $-0,12700$ & $-0,022628$ \\
\hline & & & VaR 3 & 14 & 5,6 & A & 0,056091 & $-0,043151$ & $-0,17003$ & $-0,022389$ \\
\hline \multirow{3}{*}{ PRVI3 } & \multirow{3}{*}{ SIM } & \multirow{3}{*}{2007} & VaR 1 & 20 & 8 & A & 0,080026 & $-0,024511$ & $-0,02990$ & $-0,020734$ \\
\hline & & & VaR 2 & 19 & 7,6 & A & 0,076021 & $-0,022932$ & $-0,074125$ & $-0,013813$ \\
\hline & & & VaR 3 & 21 & 8,4 & A & 0,084024 & $-0,022274$ & $-0,063449$ & $-0,012608$ \\
\hline \multirow{3}{*}{ BBRK3 } & \multirow{3}{*}{ SIM } & \multirow{3}{*}{2007} & VaR 1 & 14 & 5,6 & $\mathrm{~A}$ & 0,056025 & $-0,03160$ & $-0,03552$ & $-0,02844$ \\
\hline & & & VaR 2 & 19 & 7,6 & A & 0,076028 & $-0,02930$ & $-0,056986$ & $-0,019282$ \\
\hline & & & $\operatorname{VaR} 3$ & - & - & - & - & - & - & - \\
\hline
\end{tabular}




\begin{tabular}{|c|c|c|c|c|c|c|c|c|c|c|}
\hline Empresa & PE/VC & ANO IPO & $\begin{array}{c}\text { Metodo- } \\
\text { logia }\end{array}$ & $\begin{array}{c}\text { Número } \\
\text { de Viola- } \\
\text { ções }\end{array}$ & $\begin{array}{l}\text { Percentual } \\
\text { de Viola- } \\
\text { ções }\end{array}$ & $\begin{array}{l}\text { Teste de } \\
\text { Kupiec }\end{array}$ & $\begin{array}{l}\text { Perda de } \\
\text { Lopez }\end{array}$ & VaR Médio & $\begin{array}{l}\text { VaR Máxi- } \\
\text { mo }\end{array}$ & $\begin{array}{c}\text { VaR Míni- } \\
\text { mo }\end{array}$ \\
\hline \multirow{3}{*}{ TEMP3 } & \multirow{3}{*}{ SIM } & \multirow{3}{*}{2007} & VaR 1 & 17 & 6,8 & A & 0,068024 & $-0,03741$ & $-0,03943$ & $-0,034378$ \\
\hline & & & VaR 2 & 20 & 8 & A & 0,080027 & $-0,03652$ & $-0,04663$ & $-0,03205$ \\
\hline & & & VaR 3 & 21 & 8,4 & A & 0,084034 & $-0,03453$ & $-0,05211$ & $-0,028928$ \\
\hline \multirow{3}{*}{ RDNI3 } & \multirow{3}{*}{ NÃO } & \multirow{3}{*}{2007} & VaR 1 & 9 & 3,6 & $\mathrm{~A}$ & 0,036014 & $-0,028256$ & $-0,03419$ & $-0,023839$ \\
\hline & & & VaR 2 & 12 & 4,8 & A & 0,048016 & $-0,02573$ & $-0,04850$ & $-0,018691$ \\
\hline & & & VaR 3 & - & - & - & - & - & - & - \\
\hline \multirow{3}{*}{ TCSA3 } & \multirow{3}{*}{ NÃO } & \multirow{3}{*}{2007} & VaR 1 & 8 & 3,2 & A & 0,03201 & $-0,032808$ & $-0,03720$ & $-0,02544$ \\
\hline & & & $\mathrm{VaR} 2$ & 10 & 4 & A & 0,040009 & $-0,031173$ & $-0,065184$ & $-0,022883$ \\
\hline & & & VaR 3 & 9 & 3,6 & A & 0,03601 & $-0,030985$ & $-0,066714$ & $-0,02136$ \\
\hline \multirow{3}{*}{ IGTA3 } & \multirow{3}{*}{ NÃO } & \multirow{3}{*}{2007} & VaR 1 & 17 & 6,8 & A & 0,068012 & $-0,025349$ & $-0,029266$ & $-0,02247$ \\
\hline & & & VaR 2 & 17 & 6,8 & A & 0,068016 & $-0,023333$ & $-0,032622$ & $-0,01613$ \\
\hline & & & VaR 3 & 16 & 6,4 & $\mathrm{~A}$ & 0,064017 & $-0,023108$ & $-0,034845$ & $-0,01523$ \\
\hline \multirow{3}{*}{ SMTO3 } & \multirow{3}{*}{ NÃO } & \multirow{3}{*}{2007} & VaR 1 & 19 & 7,6 & A & 0,076012 & $-0,026182$ & $-0,027362$ & $-0,02483$ \\
\hline & & & $\mathrm{VaR} 2$ & 21 & 8,4 & A & 0,084012 & $-0,026987$ & $-0,041993$ & $-0,01725$ \\
\hline & & & VaR 3 & - & - & - & - & - & - & - \\
\hline \multirow{3}{*}{ JBSS3 } & \multirow{3}{*}{ NÃO } & \multirow{3}{*}{2007} & VaR 1 & 9 & 3,6 & A & 0,03601 & $-0,043375$ & $-0,047323$ & $-0,03870$ \\
\hline & & & VaR 2 & 10 & 4 & A & 0,040012 & $-0,04240$ & $-0,057438$ & $-0,03003$ \\
\hline & & & VaR 3 & 11 & 4,4 & A & 0,044015 & $-0,040752$ & $-0,058171$ & $-0,01786$ \\
\hline \multirow{3}{*}{ PINE4 } & \multirow{3}{*}{ NÃO } & \multirow{3}{*}{2007} & VaR 1 & 23 & 9,2 & A & 0,092026 & $-0,02403$ & $-0,02760$ & $-0,02031$ \\
\hline & & & VaR 2 & 20 & 8 & A & 0,080024 & $-0,025289$ & $-0,067078$ & $-0,01828$ \\
\hline & & & $\mathrm{VaR} 3$ & 21 & 8,4 & A & 0,084022 & $-0,025665$ & $-0,070064$ & $-0,01737$ \\
\hline
\end{tabular}




\begin{tabular}{|c|c|c|c|c|c|c|c|c|c|c|}
\hline Empresa & PE/VC & ANO IPO & $\begin{array}{c}\text { Metodo- } \\
\text { logia }\end{array}$ & $\begin{array}{l}\text { Número } \\
\text { de Viola- } \\
\text { çóes }\end{array}$ & $\begin{array}{l}\text { Percentual } \\
\text { de Viola- } \\
\text { çóes }\end{array}$ & $\begin{array}{l}\text { Teste de } \\
\text { Kupiec }\end{array}$ & $\begin{array}{l}\text { Perda de } \\
\text { Lopez }\end{array}$ & VaR Médio & $\begin{array}{l}\text { VaR Máxi- } \\
\text { mo }\end{array}$ & $\begin{array}{c}\text { VaR Míni- } \\
\text { mo }\end{array}$ \\
\hline \multirow{3}{*}{ JHSF3 } & \multirow{3}{*}{ NÃO } & \multirow{3}{*}{2007} & VaR 1 & 37 & 14,8 & $\mathrm{R}$ & 0,14807 & $-0,02949$ & $-0,037271$ & $-0,02320$ \\
\hline & & & VaR 2 & 28 & 11,2 & $\mathrm{R}$ & 0,11204 & $-0,033281$ & $-0,073515$ & $-0,01755$ \\
\hline & & & $\mathrm{VaR} 3$ & 27 & 10,8 & $\mathrm{R}$ & 0,10804 & $-0,033585$ & $-0,076614$ & $-0,01752$ \\
\hline \multirow{3}{*}{ FRIO3 } & \multirow{3}{*}{ NÃO } & \multirow{3}{*}{2007} & VaR 1 & 17 & 6,8 & A & 0,068011 & $-0,030788$ & $-0,03630$ & $-0,02594$ \\
\hline & & & VaR 2 & 17 & 6,8 & A & 0,06802 & $-0,028293$ & $-0,051631$ & 0,00996 \\
\hline & & & VaR 3 & 18 & 7,2 & A & 0,072021 & $-0,027487$ & $-0,056091$ & $-0,00993$ \\
\hline \multirow{3}{*}{ CRDE3 } & \multirow{3}{*}{ NÃO } & \multirow{3}{*}{2007} & VaR 1 & 10 & 4 & A & 0,04010 & $-0,040583$ & $-0,046371$ & $-0,03715$ \\
\hline & & & VaR 2 & 14 & 5,6 & $\mathrm{~A}$ & 0,05610 & $-0,03906$ & $-0,13863$ & $-0,02737$ \\
\hline & & & VaR 3 & 17 & 6,8 & $\mathrm{~A}$ & 0,06810 & $-0,037832$ & $-0,13134$ & $-0,02327$ \\
\hline \multirow{3}{*}{ WSON33 } & \multirow{3}{*}{ NÃO } & \multirow{3}{*}{2007} & VaR 1 & 15 & 6 & A & 0,060012 & $-0,02271$ & $-0,024947$ & $-0,020384$ \\
\hline & & & VaR 2 & 18 & 7,2 & $\mathrm{~A}$ & 0,072013 & $-0,021986$ & $-0,04865$ & $-0,017343$ \\
\hline & & & VaR 3 & 17 & 6,8 & A & 0,068013 & $-0,022064$ & $-0,049419$ & $-0,016822$ \\
\hline \multirow{3}{*}{ SFSA4 } & \multirow{3}{*}{ NÃO } & \multirow{3}{*}{2007} & VaR 1 & 21 & 8,4 & A & 0,084035 & $-0,032178$ & $-0,035434$ & $-0,02866$ \\
\hline & & & VaR 2 & 22 & 8,8 & $\mathrm{~A}$ & 0,088036 & $-0,031046$ & $-0,080963$ & $-0,020239$ \\
\hline & & & VaR 3 & 20 & 8 & $\mathrm{~A}$ & 0,080041 & $-0,030057$ & $-0,074307$ & $-0,014148$ \\
\hline \multirow{3}{*}{ PRBC4 } & \multirow{3}{*}{ NÃO } & \multirow{3}{*}{2007} & VaR 1 & 23 & 9,2 & $\mathrm{~A}$ & 0,092009 & $-0,021319$ & $-0,022892$ & $-0,02002$ \\
\hline & & & VaR 2 & 24 & 9,6 & A & 0,096008 & $-0,021023$ & $-0,033881$ & $-0,014553$ \\
\hline & & & $\operatorname{VaR} 3$ & 24 & 9,6 & A & 0,096008 & $-0,020884$ & $-0,034985$ & $-0,01450$ \\
\hline \multirow{3}{*}{ SLCE3 } & \multirow{3}{*}{ NÃO } & \multirow{3}{*}{2007} & VaR 1 & 16 & 6,4 & A & 0,06400 & $-0,02920$ & $-0,03055$ & $-0,02820$ \\
\hline & & & $\operatorname{VaR} 2$ & 19 & 7,6 & $\mathrm{~A}$ & 0,07600 & $-0,029136$ & $-0,051892$ & $-0,024737$ \\
\hline & & & $\mathrm{VaR} 3$ & 20 & 8 & A & 0,080004 & $-0,029044$ & $-0,04909$ & $-0,024067$ \\
\hline
\end{tabular}




\begin{tabular}{|c|c|c|c|c|c|c|c|c|c|c|}
\hline Empresa & PE/VC & ANO IPO & $\begin{array}{l}\text { Metodo- } \\
\text { logia }\end{array}$ & $\begin{array}{l}\text { Número } \\
\text { de Viola- } \\
\text { çóes }\end{array}$ & $\begin{array}{l}\text { Percentual } \\
\text { de Viola- } \\
\text { ções }\end{array}$ & $\begin{array}{l}\text { Teste de } \\
\text { Kupiec }\end{array}$ & $\begin{array}{c}\text { Perda de } \\
\text { Lopez }\end{array}$ & VaR Médio & $\begin{array}{l}\text { VaR Máxi- } \\
\text { mo }\end{array}$ & $\begin{array}{l}\text { VaR Míni- } \\
\text { mo }\end{array}$ \\
\hline \multirow{3}{*}{ LOGN3 } & \multirow{3}{*}{ NÃO } & \multirow{3}{*}{2007} & VaR 1 & 16 & 6,4 & A & 0,06402 & $-0,03016$ & $-0,03360$ & $-0,02821$ \\
\hline & & & VaR 2 & 14 & 5,6 & A & 0,05602 & $-0,03000$ & $-0,039743$ & $-0,026267$ \\
\hline & & & VaR 3 & 12 & 4,8 & A & 0,048019 & $-0,029764$ & $-0,038047$ & $-0,025773$ \\
\hline \multirow{3}{*}{ EZTC3 } & \multirow{3}{*}{ NÃO } & \multirow{3}{*}{2007} & VaR 1 & 24 & 9,6 & A & 0,096017 & $-0,02192$ & $-0,024313$ & $-0,01995$ \\
\hline & & & VaR 2 & 21 & 8,4 & A & 0,084017 & $-0,022975$ & $-0,039963$ & $-0,015722$ \\
\hline & & & VaR 3 & 22 & 8,8 & A & 0,088017 & $-0,022965$ & $-0,040623$ & $-0,01571$ \\
\hline \multirow{3}{*}{ DAYC4 } & \multirow{3}{*}{ NÃO } & \multirow{3}{*}{2007} & VaR 1 & 22 & 8,8 & A & 0,088025 & $-0,03119$ & $-0,032372$ & $-0,02965$ \\
\hline & & & VaR 2 & 21 & 8,4 & A & 0,084025 & $-0,030771$ & $-0,072563$ & $-0,019467$ \\
\hline & & & VaR 3 & 21 & 8,4 & A & 0,084029 & $-0,030534$ & $-0,07256$ & $-0,01930$ \\
\hline \multirow{3}{*}{ MRFG3 } & \multirow{3}{*}{ NÃO } & \multirow{3}{*}{2007} & VaR 1 & 15 & 6 & A & 0,060038 & $-0,046951$ & $-0,049448$ & $-0,04231$ \\
\hline & & & VaR 2 & 17 & 6,8 & A & 0,06804 & $-0,045578$ & $-0,093083$ & $-0,038814$ \\
\hline & & & VaR 3 & - & - & - & - & 7 & - & \\
\hline \multirow{3}{*}{ TGMA3 } & \multirow{3}{*}{ NÃO } & \multirow{3}{*}{2007} & VaR 1 & 41 & 16,4 & $\mathrm{R}$ & 0,16404 & $-0,025885$ & $-0,033727$ & $-0,020375$ \\
\hline & & & VaR 2 & 27 & 10,8 & $\mathrm{R}$ & 0,10802 & $-0,032263$ & $-0,046917$ & $-0,01821$ \\
\hline & & & VaR 3 & - & - & - & - & - & - & - \\
\hline \multirow{3}{*}{ IDVL4 } & \multirow{3}{*}{ NÃO } & \multirow{3}{*}{2007} & VaR 1 & 24 & 9,6 & A & 0,096014 & $-0,022916$ & $-0,029664$ & $-0,01858$ \\
\hline & & & VaR 2 & 20 & 8 & A & 0,080016 & $-0,021456$ & $-0,055887$ & $-0,01315$ \\
\hline & & & VaR 3 & 23 & 9,2 & A & 0,092016 & $-0,02100$ & $-0,05802$ & $-0,012337$ \\
\hline \multirow{3}{*}{ BHGR3 } & \multirow{3}{*}{ NÃO } & \multirow{3}{*}{2007} & VaR 1 & 21 & 8,4 & A & 0,084033 & $-0,023477$ & $-0,027171$ & $-0,021105$ \\
\hline & & & VaR 2 & 26 & 10,4 & $\mathrm{R}$ & 0,10403 & $-0,023415$ & $-0,065712$ & $-0,011746$ \\
\hline & & & VaR 3 & 28 & 11,2 & $\mathrm{R}$ & 0,11203 & $-0,023693$ & $-0,06764$ & $-0,011138$ \\
\hline
\end{tabular}




\begin{tabular}{|c|c|c|c|c|c|c|c|c|c|c|}
\hline Empresa & PE/VC & ANO IPO & $\begin{array}{c}\text { Metodo- } \\
\text { logia }\end{array}$ & $\begin{array}{l}\text { Número } \\
\text { de Viola- } \\
\text { çóes }\end{array}$ & $\begin{array}{l}\text { Percentual } \\
\text { de Viola- } \\
\text { çóes }\end{array}$ & $\begin{array}{l}\text { Teste de } \\
\text { Kupiec }\end{array}$ & $\begin{array}{l}\text { Perda de } \\
\text { Lopez }\end{array}$ & VaR Médio & $\begin{array}{l}\text { VaR Máxi- } \\
\text { mo }\end{array}$ & $\begin{array}{c}\text { VaR Míni- } \\
\text { mo }\end{array}$ \\
\hline \multirow{3}{*}{ BEEF3 } & \multirow{3}{*}{ NÃO } & \multirow{3}{*}{2007} & VaR 1 & 13 & 5,2 & A & 0,052008 & $-0,032488$ & $-0,035771$ & $-0,02903$ \\
\hline & & & VaR 2 & 13 & 5,2 & A & 0,052009 & $-0,031585$ & $-0,050821$ & $-0,026907$ \\
\hline & & & $\mathrm{VaR} 3$ & 13 & 5,2 & $\mathrm{~A}$ & 0,052010 & $-0,031609$ & $-0,050277$ & $-0,027076$ \\
\hline \multirow{3}{*}{ KROT3 } & \multirow{3}{*}{ NÃO } & \multirow{3}{*}{2007} & VaR 1 & 21 & 8,4 & A & 0,08402 & $-0,025934$ & $-0,02910$ & $-0,02307$ \\
\hline & & & VaR 2 & 19 & 7,6 & A & 0,076015 & $-0,026782$ & $-0,050462$ & $-0,020043$ \\
\hline & & & VaR 3 & 19 & 7,6 & A & 0,076015 & $-0,02660$ & $-0,050288$ & $-0,020068$ \\
\hline \multirow{3}{*}{ TPIS3 } & \multirow{3}{*}{ NÃO } & \multirow{3}{*}{2007} & VaR 1 & 17 & 6,8 & A & 0,068005 & $-0,02712$ & $-0,030263$ & $-0,02521$ \\
\hline & & & VaR 2 & 17 & 6,8 & $\mathrm{~A}$ & 0,068006 & $-0,026869$ & $-0,041225$ & $-0,024208$ \\
\hline & & & VaR 3 & 16 & 6,4 & $\mathrm{~A}$ & 0,064007 & $-0,026675$ & $-0,040783$ & $-0,022945$ \\
\hline \multirow{3}{*}{ ABCB4 } & \multirow{3}{*}{ NÃO } & \multirow{3}{*}{2007} & VaR 1 & 16 & 6,4 & A & 0,064006 & $-0,02831$ & $-0,029415$ & $-0,02680$ \\
\hline & & & VaR 2 & 16 & 6,4 & $\mathrm{~A}$ & 0,064006 & $-0,028287$ & $-0,033587$ & $-0,025379$ \\
\hline & & & VaR 3 & - & - & - & - & - & - & - \\
\hline \multirow{3}{*}{ MULT3 } & \multirow{3}{*}{ NÃO } & \multirow{3}{*}{2007} & VaR 1 & 19 & 7,6 & A & 0,07600 & $-0,021208$ & $-0,02578$ & $-0,01816$ \\
\hline & & & VaR 2 & 22 & 8,8 & $\mathrm{~A}$ & 0,088006 & $-0,019658$ & $-0,028555$ & $-0,014013$ \\
\hline & & & VaR 3 & - & - & - & - & - & - & - \\
\hline \multirow{3}{*}{ GSHP3 } & \multirow{3}{*}{ NÃO } & \multirow{3}{*}{2007} & VaR 1 & 13 & 5,2 & $\mathrm{~A}$ & 0,052044 & $-0,033681$ & $-0,03531$ & $-0,032441$ \\
\hline & & & VaR 2 & 16 & 6,4 & A & 0,06404 & $-0,032832$ & $-0,062073$ & $-0,022581$ \\
\hline & & & $\operatorname{VaR} 3$ & - & - & - & - & - & - & - \\
\hline \multirow{3}{*}{ ESTC3 } & \multirow{3}{*}{ NÃO } & \multirow{3}{*}{2007} & VaR 1 & 13 & 5,2 & A & 0,052007 & $-0,02410$ & $-0,026948$ & $-0,02245$ \\
\hline & & & $\operatorname{VaR} 2$ & - & - & - & - & - & - & - \\
\hline & & & $\mathrm{VaR} 3$ & 13 & 5,2 & A & 0,052006 & $-0,023872$ & $-0,032143$ & $-0,02084$ \\
\hline
\end{tabular}




\begin{tabular}{|c|c|c|c|c|c|c|c|c|c|c|}
\hline Empresa & PE/VC & ANO IPO & $\begin{array}{c}\text { Metodo- } \\
\text { logia }\end{array}$ & $\begin{array}{c}\text { Número } \\
\text { de Viola- } \\
\text { ções }\end{array}$ & $\begin{array}{l}\text { Percentual } \\
\text { de Viola- } \\
\text { ções }\end{array}$ & $\begin{array}{l}\text { Teste de } \\
\text { Kupiec }\end{array}$ & $\begin{array}{l}\text { Perda de } \\
\text { Lopez }\end{array}$ & VaR Médio & $\begin{array}{l}\text { VaR Máxi- } \\
\text { mo }\end{array}$ & $\begin{array}{c}\text { VaR Míni- } \\
\text { mo }\end{array}$ \\
\hline \multirow{3}{*}{ CZLT33 } & \multirow{3}{*}{ NÃO } & \multirow{3}{*}{2007} & VaR 1 & 14 & 5,6 & A & 0,056008 & $-0,023377$ & $-0,024228$ & $-0,022481$ \\
\hline & & & VaR 2 & 13 & 5,2 & A & 0,052007 & $-0,023226$ & $-0,036332$ & $-0,020713$ \\
\hline & & & VaR 3 & - & - & - & - & - & - & - \\
\hline \multirow{3}{*}{ SULA11 } & \multirow{3}{*}{ NÃO } & \multirow{3}{*}{2007} & VaR 1 & 7 & 2,8 & A & 0,02812 & $-0,034051$ & $-0,039231$ & $-0,030374$ \\
\hline & & & VaR 2 & 8 & 3,2 & A & 0,03212 & $-0,033125$ & $-0,088468$ & $-0,022432$ \\
\hline & & & $\mathrm{VaR} 3$ & - & - & - & - & - & - & - \\
\hline \multirow{3}{*}{ BICB4 } & \multirow{3}{*}{ NÃO } & \multirow{3}{*}{2007} & VaR 1 & 16 & 6,4 & A & 0,064017 & $-0,03246$ & $-0,034643$ & $-0,02941$ \\
\hline & & & $\mathrm{VaR} 2$ & 16 & 6,4 & A & 0,064016 & $-0,03262$ & $-0,056655$ & $-0,021538$ \\
\hline & & & VaR 3 & 16 & 6,4 & A & 0,064016 & $-0,03341$ & $-0,06099$ & $-0,021252$ \\
\hline \multirow{3}{*}{ TRIS3 } & \multirow{3}{*}{ NÃO } & \multirow{3}{*}{2007} & VaR 1 & 8 & 3,2 & A & 0,03201 & $-0,03890$ & $-0,04320$ & $-0,03379$ \\
\hline & & & VaR 2 & 11 & 4,4 & A & 0,044015 & $-0,03533$ & $-0,060751$ & $-0,019093$ \\
\hline & & & VaR 3 & 11 & 4,4 & $\mathrm{~A}$ & 0,044016 & $-0,03505$ & $-0,06160$ & $-0,018827$ \\
\hline \multirow{3}{*}{ AMAR3 } & \multirow{3}{*}{ NÃO } & \multirow{3}{*}{2007} & VaR 1 & 25 & 10 & A & 0,10003 & $-0,02658$ & $-0,030368$ & $-0,02533$ \\
\hline & & & $\mathrm{VaR} 2$ & 21 & 8,4 & A & 0,084026 & $-0,02595$ & $-0,045943$ & $-0,014559$ \\
\hline & & & VaR 3 & 22 & 8,8 & A & 0,088026 & $-0,02617$ & $-0,049413$ & $-0,013853$ \\
\hline \multirow{3}{*}{ BVMF3 } & \multirow{3}{*}{ NÃO } & \multirow{3}{*}{2007} & $\mathrm{VaR} 1$ & 16 & 6,4 & A & 0,06402 & $-0,02906$ & $-0,030752$ & $-0,02720$ \\
\hline & & & VaR 2 & 18 & 7,2 & A & 0,072015 & $-0,02849$ & $-0,054259$ & $-0,019854$ \\
\hline & & & VaR 3 & - & - & - & - & - & - & - \\
\hline \multirow{3}{*}{ HBOR3 } & \multirow{3}{*}{ NÃO } & \multirow{3}{*}{2007} & VaR 1 & 17 & 6,8 & A & 0,068013 & $-0,02915$ & $-0,031277$ & $-0,02741$ \\
\hline & & & VaR 2 & 20 & 8 & A & 0,080016 & $-0,02795$ & $-0,034409$ & $-0,021058$ \\
\hline & & & VaR 3 & 20 & 8 & A & 0,080016 & $-0,02772$ & $-0,034079$ & $-0,02119$ \\
\hline
\end{tabular}




\begin{tabular}{|c|c|c|c|c|c|c|c|c|c|c|}
\hline Empresa & PE/VC & ANO IPO & $\begin{array}{c}\text { Metodo- } \\
\text { logia }\end{array}$ & $\begin{array}{c}\text { Número } \\
\text { de Viola- } \\
\text { ções }\end{array}$ & $\begin{array}{l}\text { Percentual } \\
\text { de Viola- } \\
\text { ções }\end{array}$ & $\begin{array}{l}\text { Teste de } \\
\text { Kupiec }\end{array}$ & $\begin{array}{l}\text { Perda de } \\
\text { Lopez }\end{array}$ & VaR Médio & $\begin{array}{c}\text { VaR Máxi- } \\
\text { mo }\end{array}$ & $\begin{array}{c}\text { VaR Míni- } \\
\text { mo }\end{array}$ \\
\hline \multirow{3}{*}{ ENEV3 } & \multirow{3}{*}{ NÃO } & \multirow{3}{*}{2007} & VaR 1 & 33 & 13,2 & $\mathrm{R}$ & 0,13210 & $-0,03960$ & $-0,04923$ & $-0,03456$ \\
\hline & & & VaR 2 & 29 & 11,6 & $\mathrm{R}$ & 0,11609 & $-0,04321$ & $-0,093982$ & $-0,027614$ \\
\hline & & & $\operatorname{VaR} 3$ & 29 & 11,6 & $\mathrm{R}$ & 0,11609 & $-0,04333$ & $-0,11086$ & $-0,02660$ \\
\hline \multirow{3}{*}{ OGXP3 } & \multirow{3}{*}{ SIM } & \multirow{3}{*}{2008} & VaR 1 & 42 & 16,8 & $\mathrm{R}$ & 0,16971 & $-0,093613$ & $-0,14938$ & $-0,060983$ \\
\hline & & & VaR 2 & 31 & 12,4 & $\mathrm{R}$ & 0,12495 & $-0,12381$ & $-0,47732$ & $-0,044188$ \\
\hline & & & VaR 3 & 28 & 11,2 & $\mathrm{R}$ & 0,11297 & $-0,12682$ & $-0,47452$ & $-0,042483$ \\
\hline \multirow{3}{*}{ HYPE3 } & \multirow{3}{*}{ NÃO } & \multirow{3}{*}{2008} & VaR 1 & 7 & 2,8 & A & 0,02800 & $-0,028383$ & $-0,037032$ & $-0,022167$ \\
\hline & & & VaR 2 & 13 & 5,2 & A & 0,05200 & $-0,025166$ & $-0,040554$ & $-0,01960$ \\
\hline & & & VaR 3 & 13 & 5,2 & A & 0,05200 & $-0,025017$ & $-0,040153$ & $-0,01939$ \\
\hline \multirow{3}{*}{ LLIS3 } & \multirow{3}{*}{ NÃO } & \multirow{3}{*}{2008} & VaR 1 & 16 & 6,4 & A & 0,064023 & $-0,035644$ & $-0,037641$ & $-0,03292$ \\
\hline & & & $\operatorname{VaR} 2$ & 14 & $\overline{5,6}$ & $\bar{A}$ & 0,056024 & $-0,035437$ & $-0,05690$ & $-0,029653$ \\
\hline & & & $\mathrm{VaR} 3$ & - & - & - & - & - & - & - \\
\hline \multirow{3}{*}{ CTIP3 } & \multirow{3}{*}{ SIM } & \multirow{3}{*}{2009} & VaR 1 & 10 & 4 & A & 0,040005 & $-0,025149$ & $-0,02696$ & $-0,02138$ \\
\hline & & & VaR 2 & 11 & 4,4 & A & 0,044007 & $-0,02190$ & $-0,041325$ & $-0,011313$ \\
\hline & & & $\mathrm{VaR} 3$ & - & - & - & - & - & - & - \\
\hline \multirow{3}{*}{ DIRR3 } & \multirow{3}{*}{ SIM } & \multirow{3}{*}{2009} & VaR 1 & 18 & 7,2 & A & 0,072026 & $-0,027826$ & $-0,03010$ & $-0,02620$ \\
\hline & & & VaR 2 & 17 & 6,8 & $\mathrm{~A}$ & 0,06802 & $-0,02811$ & $-0,04660$ & $-0,013213$ \\
\hline & & & VaR 3 & 17 & 6,8 & $\bar{A}$ & 0,068021 & $-0,027973$ & $-0,04966$ & $-0,013208$ \\
\hline \multirow{3}{*}{ CIEL3 } & \multirow{3}{*}{ NÃO } & \multirow{3}{*}{2009} & VaR 1 & 11 & 4,4 & A & 0,04400 & $-0,024109$ & $-0,027191$ & $-0,01874$ \\
\hline & & & $\mathrm{VaR} 2$ & 12 & 4,8 & $\bar{A}$ & 0,048005 & $-0,020718$ & $-0,04040$ & $-0,014416$ \\
\hline & & & $\operatorname{VaR} 3$ & 14 & 5,6 & A & 0,056005 & $-0,020543$ & $-0,037569$ & $-0,014505$ \\
\hline
\end{tabular}




\begin{tabular}{|c|c|c|c|c|c|c|c|c|c|c|}
\hline Empresa & PE/VC & ANO IPO & $\begin{array}{c}\text { Metodo- } \\
\text { logia }\end{array}$ & $\begin{array}{c}\text { Número } \\
\text { de Viola- } \\
\text { ções }\end{array}$ & $\begin{array}{c}\text { Percentual } \\
\text { de Viola- } \\
\text { çóes }\end{array}$ & $\begin{array}{l}\text { Teste de } \\
\text { Kupiec }\end{array}$ & $\begin{array}{c}\text { Perda de } \\
\text { Lopez }\end{array}$ & VaR Médio & $\begin{array}{l}\text { VaR Máxi- } \\
\text { mo }\end{array}$ & $\begin{array}{c}\text { VaR Míni- } \\
\text { mo }\end{array}$ \\
\hline \multirow{3}{*}{ FLRY3 } & \multirow{3}{*}{ NÃO } & \multirow{3}{*}{2009} & VaR 1 & 10 & 4 & A & 0,040005 & $-0,022506$ & $-0,02410$ & $-0,019462$ \\
\hline & & & $\mathrm{VaR} 2$ & 17 & 6,8 & A & 0,068005 & $-0,022041$ & $-0,04520$ & $-0,015635$ \\
\hline & & & $\mathrm{VaR} 3$ & 17 & 6,8 & A & 0,068005 & $-0,021955$ & $-0,044355$ & $-0,015966$ \\
\hline \multirow{3}{*}{ BRPR3 } & \multirow{3}{*}{ SIM } & \multirow{3}{*}{2010} & $\mathrm{VaR} 1$ & 18 & 7,2 & A & 0,072016 & $-0,026147$ & $-0,02755$ & $-0,02494$ \\
\hline & & & $\mathrm{VaR} 2$ & 19 & 7,6 & A & 0,076016 & $-0,026953$ & $-0,051489$ & $-0,019746$ \\
\hline & & & VaR 3 & 20 & 8 & A & 0,080017 & $-0,02640$ & $-0,05220$ & $-0,019517$ \\
\hline \multirow{3}{*}{ MILS3 } & \multirow{3}{*}{ SIM } & \multirow{3}{*}{2010} & $\mathrm{VaR} 1$ & 13 & 5,2 & A & 0,052009 & $-0,026291$ & $-0,027927$ & $-0,024955$ \\
\hline & & & $\mathrm{VaR} 2$ & 13 & 5,2 & A & 0,052009 & $-0,025594$ & $-0,037575$ & $-0,020216$ \\
\hline & & & VaR 3 & - & - & - & - & - & - & - \\
\hline \multirow{3}{*}{ RNEW11 } & \multirow{3}{*}{ SIM } & \multirow{3}{*}{2010} & VaR 1 & 6 & 2,4 & A & 0,02400 & $-0,027654$ & $-0,03073$ & $-0,02606$ \\
\hline & & & $\mathrm{VaR} 2$ & 7 & 2,8 & A & 0,02800 & $-0,02786$ & $-0,13002$ & $-0,01805$ \\
\hline & & & VaR 3 & 7 & 2,8 & A & 0,02800 & $-0,026931$ & $-0,069219$ & $-0,012906$ \\
\hline \multirow{3}{*}{ HRTP3 } & \multirow{3}{*}{ SIM } & \multirow{3}{*}{2010} & $\mathrm{VaR} 1$ & 14 & 5,6 & A & 0,05620 & $-0,079834$ & $-0,08717$ & $-0,07544$ \\
\hline & & & $\mathrm{VaR} 2$ & 15 & 6 & A & 0,06020 & $-0,077732$ & $-0,22673$ & $-0,051674$ \\
\hline & & & VaR 3 & 16 & 6,4 & A & 0,064179 & $-0,07745$ & $-0,26054$ & $-0,046975$ \\
\hline \multirow{3}{*}{ BRIN3 } & \multirow{3}{*}{ SIM } & \multirow{3}{*}{2010} & $\mathrm{VaR} 1$ & 10 & 4 & $\mathrm{~A}$ & 0,04003 & $-0,02697$ & $-0,02854$ & $-0,02392$ \\
\hline & & & $\mathrm{VaR} 2$ & 11 & 4,4 & A & 0,04403 & $-0,02612$ & $-0,07030$ & $-0,01788$ \\
\hline & & & VaR 3 & 11 & 4,4 & A & 0,04403 & $-0,02601$ & $-0,06803$ & $-0,01769$ \\
\hline \multirow{3}{*}{ ALSC3 } & \multirow{3}{*}{ NÃO } & \multirow{3}{*}{2010} & $\mathrm{VaR} 1$ & 20 & 8 & A & 0,080011 & $-0,022387$ & $-0,024338$ & $-0,020589$ \\
\hline & & & VaR 2 & 22 & 8,8 & A & 0,088011 & $-0,022407$ & $-0,031363$ & $-0,01826$ \\
\hline & & & VaR 3 & 22 & 8,8 & A & 0,088011 & $-0,022443$ & $-0,031109$ & $-0,018138$ \\
\hline
\end{tabular}




\begin{tabular}{|c|c|c|c|c|c|c|c|c|c|c|}
\hline Empresa & PE/VC & ANO IPO & $\begin{array}{c}\text { Metodo- } \\
\text { logia }\end{array}$ & $\begin{array}{c}\text { Número } \\
\text { de Viola- } \\
\text { çóes }\end{array}$ & $\begin{array}{l}\text { Percentual } \\
\text { de Viola- } \\
\text { ções }\end{array}$ & $\begin{array}{l}\text { Teste de } \\
\text { Kupiec }\end{array}$ & $\begin{array}{l}\text { Perda de } \\
\text { Lopez }\end{array}$ & VaR Médio & $\begin{array}{l}\text { VaR Máxi- } \\
\text { mo }\end{array}$ & $\begin{array}{c}\text { VaR Míni- } \\
\text { mo }\end{array}$ \\
\hline \multirow{3}{*}{ MPLU3 } & \multirow{3}{*}{ NÃO } & \multirow{3}{*}{2010} & VaR 1 & 20 & 8 & A & 0,080064 & $-0,033365$ & $-0,036209$ & $-0,02970$ \\
\hline & & & VaR 2 & 21 & 8,4 & A & 0,084061 & $-0,033654$ & $-0,070992$ & $-0,025867$ \\
\hline & & & VaR 3 & - & - & - & - & - & - & - \\
\hline \multirow{3}{*}{ OSXB3 } & \multirow{3}{*}{ NÃO } & \multirow{3}{*}{2010} & $\mathrm{VaR} 1$ & 41 & 16,4 & $\mathrm{R}$ & 0,16487 & $-0,070731$ & $-0,11417$ & $-0,04129$ \\
\hline & & & VaR 2 & 26 & 10,4 & $\mathrm{R}$ & 0,10447 & $-0,10454$ & $-0,23143$ & $-0,034576$ \\
\hline & & & VaR 3 & 27 & 10,8 & $\mathrm{R}$ & 0,10846 & $-0,10407$ & $-0,26978$ & $-0,030767$ \\
\hline \multirow{3}{*}{ ECOR3 } & \multirow{3}{*}{ NÃO } & \multirow{3}{*}{2010} & VaR 1 & 19 & 7,6 & A & 0,076009 & $-0,020438$ & $-0,02431$ & $-0,01833$ \\
\hline & & & $\mathrm{VaR} 2$ & 18 & 7,2 & $\mathrm{~A}$ & 0,072009 & $-0,01931$ & $-0,032635$ & $-0,013782$ \\
\hline & & & VaR 3 & 18 & 7,2 & A & 0,072009 & $-0,019213$ & $-0,03980$ & $-0,01353$ \\
\hline
\end{tabular}




\section{APÊNDICE B - VAR COMPLETO POR ORDEM DE VAR MÉDIO}

\begin{tabular}{|c|c|c|c|c|}
\hline Empresa & PE/VC & VaR Mínimo & VaR Médio & VaR Máximo \\
\hline LUPA3 & SIM & $-0,02866$ & $-0,09383$ & $-0,64066$ \\
\hline MMXM3 & NÃO & $-0,03493$ & $-0,09036$ & $-0,26656$ \\
\hline HRTP3 & SIM & $-0,07544$ & $-0,07983$ & $-0,08717$ \\
\hline VIVR3 & SIM & $-0,03814$ & $-0,07721$ & $-0,24017$ \\
\hline GFSA3 & SIM & $-0,05217$ & $-0,05864$ & $-0,06265$ \\
\hline BISA3 & NÃO & $-0,04832$ & $-0,05072$ & $-0,05373$ \\
\hline PDGR3 & SIM & $-0,04572$ & $-0,05022$ & $-0,05447$ \\
\hline MRFG3 & NÃO & $-0,04231$ & $-0,04695$ & $-0,04945$ \\
\hline MRVE3 & SIM & $-0,02425$ & $-0,04570$ & $-0,08370$ \\
\hline JBSS3 & NÃO & $-0,03870$ & $-0,04338$ & $-0,04732$ \\
\hline SGPS3 & SIM & $-0,02239$ & $-0,04315$ & $-0,17003$ \\
\hline CRDE3 & NÃO & $-0,03715$ & $-0,04058$ & $-0,04637$ \\
\hline TRIS3 & NÃO & $-0,03379$ & $-0,03890$ & $-0,04320$ \\
\hline VAGR3 & NÃO & $-0,03189$ & $-0,03778$ & $-0,04629$ \\
\hline TEMP3 & SIM & $-0,03438$ & $-0,03741$ & $-0,03943$ \\
\hline POSI3 & NÃO & $-0,03436$ & $-0,03670$ & $-0,04066$ \\
\hline PFRM3 & NÃO & $-0,02824$ & $-0,03666$ & $-0,04018$ \\
\hline LLIS3 & NÃO & $-0,02965$ & $-0,03544$ & $-0,05690$ \\
\hline CARD3 & SIM & $-0,02207$ & $-0,03441$ & $-0,06157$ \\
\hline SULA11 & NÃO & $-0,03037$ & $-0,03405$ & $-0,03923$ \\
\hline GSHP3 & NÃO & $-0,03244$ & $-0,03368$ & $-0,03531$ \\
\hline BICB4 & NÃO & $-0,02125$ & $-0,03341$ & $-0,06099$ \\
\hline MPLU3 & NÃO & $-0,02970$ & $-0,03337$ & $-0,03621$ \\
\hline GPIV33 & SIM & $-0,02922$ & $-0,03298$ & $-0,03896$ \\
\hline TCSA3 & NÃO & $-0,02544$ & $-0,03281$ & $-0,03720$ \\
\hline BEEF3 & NÃO & $-0,02903$ & $-0,03249$ & $-0,03577$ \\
\hline BBRK3 & SIM & $-0,02844$ & $-0,03160$ & $-0,03552$ \\
\hline EVEN3 & SIM & $-0,02434$ & $-0,03133$ & $-0,06909$ \\
\hline BEMA3 & SIM & $-0,01420$ & $-0,03104$ & $-0,07860$ \\
\hline FRIO3 & NÃO & $-0,02594$ & $-0,03079$ & $-0,03630$ \\
\hline DAYC4 & NÃO & $-0,01947$ & $-0,03077$ & $-0,07256$ \\
\hline SFSA4 & NÃO & $-0,01415$ & $-0,03006$ & $-0,07431$ \\
\hline LOGN3 & NÃO & $-0,02577$ & $-0,02976$ & $-0,03805$ \\
\hline SLCE3 & NÃO & $-0,02820$ & $-0,02920$ & $-0,03055$ \\
\hline
\end{tabular}




\begin{tabular}{|c|c|c|c|c|}
\hline Empresa & PE/VC & VaR Mínimo & VaR Médio & VaR Máximo \\
\hline HBOR3 & NÃO & $-0,02741$ & $-0,02915$ & $-0,03128$ \\
\hline BVMF3 & NÃO & $-0,02720$ & $-0,02906$ & $-0,03075$ \\
\hline ODPV3 & SIM & $-0,02651$ & $-0,02841$ & $-0,03043$ \\
\hline HYPE3 & NÃO & $-0,02217$ & $-0,02838$ & $-0,03703$ \\
\hline ABCB4 & NÃO & $-0,02538$ & $-0,02829$ & $-0,03359$ \\
\hline RDNI3 & NÃO & $-0,02384$ & $-0,02826$ & $-0,03419$ \\
\hline DIRR3 & SIM & $-0,01321$ & $-0,02811$ & $-0,04660$ \\
\hline RNEW11 & SIM & $-0,02606$ & $-0,02765$ & $-0,03073$ \\
\hline CSMG3 & NÃO & $-0,01969$ & $-0,02728$ & $-0,04100$ \\
\hline BRML3 & SIM & $-0,02529$ & $-0,02727$ & $-0,03031$ \\
\hline BRIN3 & SIM & $-0,02392$ & $-0,02697$ & $-0,02854$ \\
\hline KROT3 & NÃO & $-0,02004$ & $-0,02678$ & $-0,05046$ \\
\hline LPSB3 & NÃO & $-0,01111$ & $-0,02668$ & $-0,03883$ \\
\hline TPIS3 & NÃO & $-0,02295$ & $-0,02668$ & $-0,04078$ \\
\hline CREM3 & SIM & $-0,02261$ & $-0,02647$ & $-0,07614$ \\
\hline MILS3 & SIM & $-0,02496$ & $-0,02629$ & $-0,02793$ \\
\hline SMTO3 & NÃO & $-0,02483$ & $-0,02618$ & $-0,02736$ \\
\hline BRPR3 & SIM & $-0,02494$ & $-0,02615$ & $-0,02755$ \\
\hline TOTS3 & SIM & $-0,02256$ & $-0,02608$ & $-0,04140$ \\
\hline EQTL3 & SIM & $-0,02016$ & $-0,02600$ & $-0,02886$ \\
\hline AMAR3 & NÃO & $-0,01456$ & $-0,02595$ & $-0,04594$ \\
\hline PINE4 & NÃO & $-0,01828$ & $-0,02529$ & $-0,06708$ \\
\hline CTIP3 & SIM & $-0,02138$ & $-0,02515$ & $-0,02696$ \\
\hline VLID3 & NÃO & $-0,02290$ & $-0,02503$ & $-0,02776$ \\
\hline DAGB33 & NÃO & $-0,02012$ & $-0,02502$ & $-0,03285$ \\
\hline TAEE11 & NÃO & $-0,01908$ & $-0,02436$ & $-0,02997$ \\
\hline CIEL3 & NÃO & $-0,01874$ & $-0,02411$ & $-0,02719$ \\
\hline ESTC3 & NÃO & $-0,02084$ & $-0,02387$ & $-0,03214$ \\
\hline BHGR3 & NÃO & $-0,02111$ & $-0,02348$ & $-0,02717$ \\
\hline CZLT33 & NÃO & $-0,02071$ & $-0,02323$ & $-0,03633$ \\
\hline IGTA3 & NÃO & $-0,01523$ & $-0,02311$ & $-0,03485$ \\
\hline EZTC3 & NÃO & $-0,01572$ & $-0,02298$ & $-0,03996$ \\
\hline PRVI3 & SIM & $-0,01381$ & $-0,02293$ & $-0,07413$ \\
\hline WSON33 & NÃO & $-0,02038$ & $-0,02271$ & $-0,02495$ \\
\hline FLRY3 & NÃO & $-0,01946$ & $-0,02251$ & $-0,02410$ \\
\hline ALSC3 & NÃO & $-0,02059$ & $-0,02239$ & $-0,02434$ \\
\hline IDVL4 & NÃO & $-0,01315$ & $-0,02146$ & $-0,05589$ \\
\hline
\end{tabular}


Júlio Pereira de Araújo, Marcos Roberto Gois de Oliveira

\begin{tabular}{|c|c|r|r|r|}
\hline Empresa & PE/VC & VaR Mínimo & VaR Médio & \multicolumn{1}{c|}{ VaR Máximo } \\
\hline PRBC4 & NÃO & $-0,02002$ & $-0,02132$ & $-0,02289$ \\
\hline MULT3 & NÃO & $-0,01816$ & $-0,02121$ & $-0,02578$ \\
\hline MDIA3 & NÃO & $-0,01853$ & $-0,02007$ & $-0,02772$ \\
\hline ECOR3 & NÃO & $-0,01353$ & $-0,01921$ & $-0,03980$ \\
\hline OGXP3 & SIM & - & - & - \\
\hline JHSF3 & NÃO & - & - & - \\
\hline TGMA3 & NÃO & - & - & - \\
\hline ENEV3 & NÃO & - & - & - \\
\hline OSXB3 & NÃO & - & - & \\
\hline
\end{tabular}

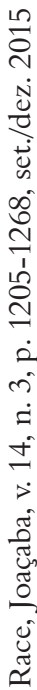




\section{APÊNDICE C - VAR COMPLETO POR ORDEM DE VAR MÁXIMO}

\begin{tabular}{|c|c|c|c|c|}
\hline Empresa & PE/VC & VaR Mínimo & VaR Médio & VaR Máximo \\
\hline LUPA3 & SIM & $-0,02866$ & $-0,09383$ & $-0,64066$ \\
\hline MMXM3 & NÃO & $-0,03493$ & $-0,09036$ & $-0,26656$ \\
\hline VIVR3 & SIM & $-0,03814$ & $-0,07721$ & $-0,24017$ \\
\hline SGPS3 & SIM & $-0,02239$ & $-0,04315$ & $-0,17003$ \\
\hline HRTP3 & SIM & $-0,07544$ & $-0,07983$ & $-0,08717$ \\
\hline MRVE3 & SIM & $-0,02425$ & $-0,04570$ & $-0,08370$ \\
\hline BEMA3 & SIM & $-0,01420$ & $-0,03104$ & $-0,07860$ \\
\hline CREM3 & SIM & $-0,02261$ & $-0,02647$ & $-0,07614$ \\
\hline SFSA4 & NÃO & $-0,01415$ & $-0,03006$ & $-0,07431$ \\
\hline PRVI3 & SIM & $-0,01381$ & $-0,02293$ & $-0,07413$ \\
\hline DAYC4 & $\mathrm{NÃO}$ & $-0,01947$ & $-0,03077$ & $-0,07256$ \\
\hline EVEN3 & SIM & $-0,02434$ & $-0,03133$ & $-0,06909$ \\
\hline PINE4 & NÃO & $-0,01828$ & $-0,02529$ & $-0,06708$ \\
\hline GFSA3 & SIM & $-0,05217$ & $-0,05864$ & $-0,06265$ \\
\hline CARD3 & SIM & $-0,02207$ & $-0,03441$ & $-0,06157$ \\
\hline BICB4 & NÃO & $-0,02125$ & $-0,03341$ & $-0,06099$ \\
\hline LLIS3 & $\mathrm{NÃO}$ & $-0,02965$ & $-0,03544$ & $-0,05690$ \\
\hline IDVL4 & $\mathrm{NÃO}$ & $-0,01315$ & $-0,02146$ & $-0,05589$ \\
\hline PDGR3 & SIM & $-0,04572$ & $-0,05022$ & $-0,05447$ \\
\hline BISA3 & NÃO & $-0,04832$ & $-0,05072$ & $-0,05373$ \\
\hline KROT3 & NÃO & $-0,02004$ & $-0,02678$ & $-0,05046$ \\
\hline MRFG3 & NÃO & $-0,04231$ & $-0,04695$ & $-0,04945$ \\
\hline JBSS3 & NÃO & $-0,03870$ & $-0,04338$ & $-0,04732$ \\
\hline DIRR3 & SIM & $-0,01321$ & $-0,02811$ & $-0,04660$ \\
\hline CRDE3 & NÃO & $-0,03715$ & $-0,04058$ & $-0,04637$ \\
\hline VAGR3 & NÃO & $-0,03189$ & $-0,03778$ & $-0,04629$ \\
\hline AMAR3 & NÃO & $-0,01456$ & $-0,02595$ & $-0,04594$ \\
\hline TRIS3 & NÃO & $-0,03379$ & $-0,03890$ & $-0,04320$ \\
\hline TOTS3 & SIM & $-0,02256$ & $-0,02608$ & $-0,04140$ \\
\hline CSMG3 & NÃO & $-0,01969$ & $-0,02728$ & $-0,04100$ \\
\hline TPIS3 & NÃO & $-0,02295$ & $-0,02668$ & $-0,04078$ \\
\hline POSI3 & NÃO & $-0,03436$ & $-0,03670$ & $-0,04066$ \\
\hline PFRM3 & NÃO & $-0,02824$ & $-0,03666$ & $-0,04018$ \\
\hline EZTC3 & NÃO & $-0,01572$ & $-0,02298$ & $-0,03996$ \\
\hline ECOR3 & NÃO & $-0,01353$ & $-0,01921$ & $-0,03980$ \\
\hline
\end{tabular}




\begin{tabular}{|c|c|c|c|c|}
\hline Empresa & PE/VC & VaR Mínimo & VaR Médio & VaR Máximo \\
\hline TEMP3 & SIM & $-0,03438$ & $-0,03741$ & $-0,03943$ \\
\hline SULA11 & NÃO & $-0,03037$ & $-0,03405$ & $-0,03923$ \\
\hline GPIV33 & SIM & $-0,02922$ & $-0,03298$ & $-0,03896$ \\
\hline LPSB3 & NÃO & $-0,01111$ & $-0,02668$ & $-0,03883$ \\
\hline LOGN3 & NÃO & $-0,02577$ & $-0,02976$ & $-0,03805$ \\
\hline TCSA3 & NÃO & $-0,02544$ & $-0,03281$ & $-0,03720$ \\
\hline HYPE3 & NÃO & $-0,02217$ & $-0,02838$ & $-0,03703$ \\
\hline CZLT33 & NÃO & $-0,02071$ & $-0,02323$ & $-0,03633$ \\
\hline FRIO3 & NÃO & $-0,02594$ & $-0,03079$ & $-0,03630$ \\
\hline MPLU3 & NÃO & $-0,02970$ & $-0,03337$ & $-0,03621$ \\
\hline BEEF3 & NÃO & $-0,02903$ & $-0,03249$ & $-0,03577$ \\
\hline BBRK3 & SIM & $-0,02844$ & $-0,03160$ & $-0,03552$ \\
\hline GSHP3 & NÃO & $-0,03244$ & $-0,03368$ & $-0,03531$ \\
\hline IGTA3 & NÃO & $-0,01523$ & $-0,02311$ & $-0,03485$ \\
\hline RDNI3 & NÃO & $-0,02384$ & $-0,02826$ & $-0,03419$ \\
\hline $\mathrm{ABCB} 4$ & NÃO & $-0,02538$ & $-0,02829$ & $-0,03359$ \\
\hline DAGB33 & NÃO & $-0,02012$ & $-0,02502$ & $-0,03285$ \\
\hline ESTC3 & NÃO & $-0,02084$ & $-0,02387$ & $-0,03214$ \\
\hline HBOR3 & NÃO & $-0,02741$ & $-0,02915$ & $-0,03128$ \\
\hline BVMF3 & NÃO & $-0,02720$ & $-0,02906$ & $-0,03075$ \\
\hline RNEW11 & SIM & $-0,02606$ & $-0,02765$ & $-0,03073$ \\
\hline SLCE3 & NÃO & $-0,02820$ & $-0,02920$ & $-0,03055$ \\
\hline ODPV3 & SIM & $-0,02651$ & $-0,02841$ & $-0,03043$ \\
\hline BRML3 & SIM & $-0,02529$ & $-0,02727$ & $-0,03031$ \\
\hline TAEE11 & NÃO & $-0,01908$ & $-0,02436$ & $-0,02997$ \\
\hline EQTL3 & SIM & $-0,02016$ & $-0,02600$ & $-0,02886$ \\
\hline BRIN3 & SIM & $-0,02392$ & $-0,02697$ & $-0,02854$ \\
\hline MILS3 & SIM & $-0,02496$ & $-0,02629$ & $-0,02793$ \\
\hline VLID3 & NÃO & $-0,02290$ & $-0,02503$ & $-0,02776$ \\
\hline MDIA3 & NÃO & $-0,01853$ & $-0,02007$ & $-0,02772$ \\
\hline BRPR3 & SIM & $-0,02494$ & $-0,02615$ & $-0,02755$ \\
\hline SMTO3 & NÃO & $-0,02483$ & $-0,02618$ & $-0,02736$ \\
\hline CIEL3 & NÃO & $-0,01874$ & $-0,02411$ & $-0,02719$ \\
\hline BHGR3 & NÃO & $-0,02111$ & $-0,02348$ & $-0,02717$ \\
\hline CTIP3 & SIM & $-0,02138$ & $-0,02515$ & $-0,02696$ \\
\hline MULT3 & NÃO & $-0,01816$ & $-0,02121$ & $-0,02578$ \\
\hline
\end{tabular}




\begin{tabular}{|c|c|r|r|r|}
\hline Empresa & PE/VC & VaR Mínimo & VaR Médio & VaR Máximo \\
\hline WSON33 & NÃO & $-0,02038$ & $-0,02271$ & $-0,02495$ \\
\hline ALSC3 & NÃO & $-0,02059$ & $-0,02239$ & $-0,02434$ \\
\hline FLRY3 & NÃO & $-0,01946$ & $-0,02251$ & $-0,02410$ \\
\hline PRBC4 & NÃO & $-0,02002$ & $-0,02132$ & $-0,02289$ \\
\hline OGXP3 & SIM & - & - & - \\
\hline JHSF3 & NÃO & - & - & - \\
\hline TGMA3 & NÃO & - & - & - \\
\hline ENEV3 & NÃO & - & - & - \\
\hline OSXB3 & NÃO & - & - & - \\
\hline
\end{tabular}




\section{APÊNDICE D - VAR COMPLETO POR ORDEM DE VAR MÍNIMO}

\begin{tabular}{|c|c|c|c|c|}
\hline Empresa & PE/VC & VaR Mínimo & VaR Médio & VaR Máximo \\
\hline HRTP3 & SIM & $-0,07544$ & $-0,07983$ & $-0,08717$ \\
\hline GFSA3 & SIM & $-0,05217$ & $-0,05864$ & $-0,06265$ \\
\hline BISA3 & NÃO & $-0,04832$ & $-0,05072$ & $-0,05373$ \\
\hline PDGR3 & SIM & $-0,04572$ & $-0,05022$ & $-0,05447$ \\
\hline MRFG3 & NÃO & $-0,04231$ & $-0,04695$ & $-0,04945$ \\
\hline JBSS3 & NÃO & $-0,03870$ & $-0,04338$ & $-0,04732$ \\
\hline VIVR3 & SIM & $-0,03814$ & $-0,07721$ & $-0,24017$ \\
\hline CRDE3 & NÃO & $-0,03715$ & $-0,04058$ & $-0,04637$ \\
\hline MMXM3 & NÃO & $-0,03493$ & $-0,09036$ & $-0,26656$ \\
\hline TEMP3 & SIM & $-0,03438$ & $-0,03741$ & $-0,03943$ \\
\hline POSI3 & NÃO & $-0,03436$ & $-0,03670$ & $-0,04066$ \\
\hline TRIS3 & NÃO & $-0,03379$ & $-0,03890$ & $-0,04320$ \\
\hline GSHP3 & NÃO & $-0,03244$ & $-0,03368$ & $-0,03531$ \\
\hline VAGR3 & NÃO & $-0,03189$ & $-0,03778$ & $-0,04629$ \\
\hline SULA11 & NÃO & $-0,03037$ & $-0,03405$ & $-0,03923$ \\
\hline MPLU3 & NÃO & $-0,02970$ & $-0,03337$ & $-0,03621$ \\
\hline LLIS3 & NÃO & $-0,02965$ & $-0,03544$ & $-0,05690$ \\
\hline GPIV33 & SIM & $-0,02922$ & $-0,03298$ & $-0,03896$ \\
\hline BEEF3 & NÃO & $-0,02903$ & $-0,03249$ & $-0,03577$ \\
\hline LUPA3 & SIM & $-0,02866$ & $-0,09383$ & $-0,64066$ \\
\hline BBRK3 & SIM & $-0,02844$ & $-0,03160$ & $-0,03552$ \\
\hline PFRM3 & NÃO & $-0,02824$ & $-0,03666$ & $-0,04018$ \\
\hline SLCE3 & NÃO & $-0,02820$ & $-0,02920$ & $-0,03055$ \\
\hline HBOR3 & NÃO & $-0,02741$ & $-0,02915$ & $-0,03128$ \\
\hline BVMF3 & NÃO & $-0,02720$ & $-0,02906$ & $-0,03075$ \\
\hline ODPV3 & SIM & $-0,02651$ & $-0,02841$ & $-0,03043$ \\
\hline RNEW11 & SIM & $-0,02606$ & $-0,02765$ & $-0,03073$ \\
\hline FRIO3 & NÃO & $-0,02594$ & $-0,03079$ & $-0,03630$ \\
\hline LOGN3 & NÃO & $-0,02577$ & $-0,02976$ & $-0,03805$ \\
\hline TCSA3 & NÃO & $-0,02544$ & $-0,03281$ & $-0,03720$ \\
\hline ABCB4 & NÃO & $-0,02538$ & $-0,02829$ & $-0,03359$ \\
\hline BRML3 & SIM & $-0,02529$ & $-0,02727$ & $-0,03031$ \\
\hline MILS3 & SIM & $-0,02496$ & $-0,02629$ & $-0,02793$ \\
\hline BRPR3 & SIM & $-0,02494$ & $-0,02615$ & $-0,02755$ \\
\hline SMTO3 & NÃO & $-0,02483$ & $-0,02618$ & $-0,02736$ \\
\hline
\end{tabular}




\begin{tabular}{|c|c|c|c|c|}
\hline Empresa & PE/VC & VaR Mínimo & VaR Médio & VaR Máximo \\
\hline EVEN3 & SIM & $-0,02434$ & $-0,03133$ & $-0,06909$ \\
\hline MRVE3 & SIM & $-0,02425$ & $-0,04570$ & $-0,08370$ \\
\hline BRIN3 & SIM & $-0,02392$ & $-0,02697$ & $-0,02854$ \\
\hline RDNI3 & NÃO & $-0,02384$ & $-0,02826$ & $-0,03419$ \\
\hline Empresa & $\mathrm{PE} / \mathrm{VC}$ & VaR Mínimo & VaR Médio & VaR Máximo \\
\hline TPIS3 & NÃO & $-0,02295$ & $-0,02668$ & $-0,04078$ \\
\hline VLID3 & NÃO & $-0,02290$ & $-0,02503$ & $-0,02776$ \\
\hline CREM3 & SIM & $-0,02261$ & $-0,02647$ & $-0,07614$ \\
\hline TOTS3 & SIM & $-0,02256$ & $-0,02608$ & $-0,04140$ \\
\hline SGPS3 & SIM & $-0,02239$ & $-0,04315$ & $-0,17003$ \\
\hline HYPE3 & NÃO & $-0,02217$ & $-0,02838$ & $-0,03703$ \\
\hline CARD3 & SIM & $-0,02207$ & $-0,03441$ & $-0,06157$ \\
\hline CTIP3 & SIM & $-0,02138$ & $-0,02515$ & $-0,02696$ \\
\hline BICB4 & NÃO & $-0,02125$ & $-0,03341$ & $-0,06099$ \\
\hline BHGR3 & NÃO & $-0,02111$ & $-0,02348$ & $-0,02717$ \\
\hline ESTC3 & NÃO & $-0,02084$ & $-0,02387$ & $-0,03214$ \\
\hline CZLT33 & NÃO & $-0,02071$ & $-0,02323$ & $-0,03633$ \\
\hline ALSC3 & NÃO & $-0,02059$ & $-0,02239$ & $-0,02434$ \\
\hline WSON33 & NÃO & $-0,02038$ & $-0,02271$ & $-0,02495$ \\
\hline EQTL3 & SIM & $-0,02016$ & $-0,02600$ & $-0,02886$ \\
\hline DAGB33 & NÃO & $-0,02012$ & $-0,02502$ & $-0,03285$ \\
\hline KROT3 & NÃO & $-0,02004$ & $-0,02678$ & $-0,05046$ \\
\hline PRBC4 & NÃO & $-0,02002$ & $-0,02132$ & $-0,02289$ \\
\hline CSMG3 & NÃO & $-0,01969$ & $-0,02728$ & $-0,04100$ \\
\hline DAYC4 & NÃO & $-0,01947$ & $-0,03077$ & $-0,07256$ \\
\hline FLRY3 & NÃO & $-0,01946$ & $-0,02251$ & $-0,02410$ \\
\hline TAEE11 & NÃO & $-0,01908$ & $-0,02436$ & $-0,02997$ \\
\hline CIEL3 & NÃO & $-0,01874$ & $-0,02411$ & $-0,02719$ \\
\hline MDIA3 & NÃO & $-0,01853$ & $-0,02007$ & $-0,02772$ \\
\hline PINE4 & NÃO & $-0,01828$ & $-0,02529$ & $-0,06708$ \\
\hline MULT3 & NÃO & $-0,01816$ & $-0,02121$ & $-0,02578$ \\
\hline EZTC3 & NÃO & $-0,01572$ & $-0,02298$ & $-0,03996$ \\
\hline IGTA3 & NÃO & $-0,01523$ & $-0,02311$ & $-0,03485$ \\
\hline AMAR3 & NÃO & $-0,01456$ & $-0,02595$ & $-0,04594$ \\
\hline BEMA3 & SIM & $-0,01420$ & $-0,03104$ & $-0,07860$ \\
\hline SFSA4 & NÃO & $-0,01415$ & $-0,03006$ & $-0,07431$ \\
\hline PRVI3 & SIM & $-0,01381$ & $-0,02293$ & $-0,07413$ \\
\hline
\end{tabular}


Júlio Pereira de Araújo, Marcos Roberto Gois de Oliveira

\begin{tabular}{|c|c|r|r|r|}
\hline Empresa & PE/VC & VaR Mínimo & VaR Médio & VaR Máximo \\
\hline ECOR3 & NÃO & $-0,01353$ & $-0,01921$ & $-0,03980$ \\
\hline DIRR3 & SIM & $-0,01321$ & $-0,02811$ & $-0,04660$ \\
\hline IDVL4 & NÃO & $-0,01315$ & $-0,02146$ & $-0,05589$ \\
\hline LPSB3 & NÃO & $-0,01111$ & $-0,02668$ & $-0,03883$ \\
\hline OGXP3 & SIM & - & - & - \\
\hline JHSF3 & NÃO & - & - & - \\
\hline TGMA3 & NÃO & - & - & - \\
\hline ENEV3 & NÃO & - & - & - \\
\hline OSXB3 & NÃO & - & - & \\
\hline
\end{tabular}

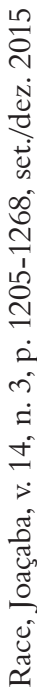




\section{APÊNDICE E - VAR 2006 POR ORDEM DE VAR MÉDIO}

\begin{tabular}{|c|c|r|r|r|}
\hline Empresa & PE/VC & VaR Mínimo & VaR Médio & VaR Máximo \\
\hline LUPA3 & SIM & $-0,02866$ & $-0,09383$ & $-0,64066$ \\
\hline MMXM3 & NÃO & $-0,03493$ & $-0,09036$ & $-0,26656$ \\
\hline GFSA3 & SIM & $-0,05217$ & $-0,05864$ & $-0,06265$ \\
\hline BISA3 & NÃO & $-0,04832$ & $-0,05072$ & $-0,05373$ \\
\hline VAGR3 & NÃO & $-0,03189$ & $-0,03778$ & $-0,04629$ \\
\hline POSI3 & NÃO & $-0,03436$ & $-0,03670$ & $-0,04066$ \\
\hline PFRM3 & NÃO & $-0,02824$ & $-0,03666$ & $-0,04018$ \\
\hline CARD3 & SIM & $-0,02207$ & $-0,03441$ & $-0,06157$ \\
\hline GPIV33 & SIM & $-0,02922$ & $-0,03298$ & $-0,03896$ \\
\hline ODPV3 & SIM & $-0,02651$ & $-0,02841$ & $-0,03043$ \\
\hline CSMG3 & NÃO & $-0,01969$ & $-0,02728$ & $-0,04100$ \\
\hline LPSB3 & NÃO & $-0,01111$ & $-0,02668$ & $-0,03883$ \\
\hline TOTS3 & SIM & $-0,02256$ & $-0,02608$ & $-0,04140$ \\
\hline EQTL3 & SIM & $-0,02016$ & $-0,02600$ & $-0,02886$ \\
\hline VLID3 & NÃO & $-0,02290$ & $-0,02503$ & $-0,02776$ \\
\hline DAGB33 & NÃO & $-0,02012$ & $-0,02502$ & $-0,03285$ \\
\hline TAEE11 & NÃO & $-0,01908$ & $-0,02436$ & $-0,02997$ \\
\hline MDIA3 & NÃO & $-0,01853$ & $-0,02007$ & $-0,02772$ \\
\hline
\end{tabular}




\section{APÊNDICE F - VAR 2006 POR ORDEM DE VAR MÁXIMO}

\begin{tabular}{|c|c|r|r|r|}
\hline Empresa & PE/VC & VaR Mínimo & VaR Médio & VaR Máximo \\
\hline LUPA3 & SIM & $-0,02866$ & $-0,09383$ & $-0,64066$ \\
\hline MMXM3 & NÃO & $-0,03493$ & $-0,09036$ & $-0,26656$ \\
\hline GFSA3 & SIM & $-0,05217$ & $-0,05864$ & $-0,06265$ \\
\hline CARD3 & SIM & $-0,02207$ & $-0,03441$ & $-0,06157$ \\
\hline BISA3 & NÃO & $-0,04832$ & $-0,05072$ & $-0,05373$ \\
\hline VAGR3 & NÃO & $-0,03189$ & $-0,03778$ & $-0,04629$ \\
\hline TOTS3 & SIM & $-0,02256$ & $-0,02608$ & $-0,04140$ \\
\hline CSMG3 & NÃO & $-0,01969$ & $-0,02728$ & $-0,04100$ \\
\hline POSI3 & NÃO & $-0,03436$ & $-0,03670$ & $-0,04066$ \\
\hline PFRM3 & NÃO & $-0,02824$ & $-0,03666$ & $-0,04018$ \\
\hline GPIV33 & SIM & $-0,02922$ & $-0,03298$ & $-0,03896$ \\
\hline LPSB3 & NÃO & $-0,01111$ & $-0,02668$ & $-0,03883$ \\
\hline DAGB33 & NÃO & $-0,02012$ & $-0,02502$ & $-0,03285$ \\
\hline ODPV3 & SIM & $-0,02651$ & $-0,02841$ & $-0,03043$ \\
\hline TAEE11 & NÃO & $-0,01908$ & $-0,02436$ & $-0,02997$ \\
\hline EQTL3 & SIM & $-0,02016$ & $-0,02600$ & $-0,02886$ \\
\hline VLID3 & NÃO & $-0,02290$ & $-0,02503$ & $-0,02776$ \\
\hline MDIA3 & NÃO & $-0,01853$ & $-0,02007$ & $-0,02772$ \\
\hline & & & &
\end{tabular}




\section{APÊNDICE G - VAR 2006 POR ORDEM DE VAR MÍNIMO}

\begin{tabular}{|c|c|r|r|r|}
\hline Empresa & PE/VC & VaR Mínimo & VaR Médio & VaR Máximo \\
\hline GFSA3 & SIM & $-0,05217$ & $-0,05864$ & $-0,06265$ \\
\hline BISA3 & NÃO & $-0,04832$ & $-0,05072$ & $-0,05373$ \\
\hline MMXM3 & NÃO & $-0,03493$ & $-0,09036$ & $-0,26656$ \\
\hline POSI3 & NÃO & $-0,03436$ & $-0,03670$ & $-0,04066$ \\
\hline VAGR3 & NÃO & $-0,03189$ & $-0,03778$ & $-0,04629$ \\
\hline GPIV33 & SIM & $-0,02922$ & $-0,03298$ & $-0,03896$ \\
\hline LUPA3 & SIM & $-0,02866$ & $-0,09383$ & $-0,64066$ \\
\hline PFRM3 & NÃO & $-0,02824$ & $-0,03666$ & $-0,04018$ \\
\hline ODPV3 & SIM & $-0,02651$ & $-0,02841$ & $-0,03043$ \\
\hline VLID3 & NÃO & $-0,02290$ & $-0,02503$ & $-0,02776$ \\
\hline TOTS3 & SIM & $-0,02256$ & $-0,02608$ & $-0,04140$ \\
\hline CARD3 & SIM & $-0,02207$ & $-0,03441$ & $-0,06157$ \\
\hline EQTL3 & SIM & $-0,02016$ & $-0,02600$ & $-0,02886$ \\
\hline DAGB33 & NÃO & $-0,02012$ & $-0,02502$ & $-0,03285$ \\
\hline CSMG3 & NÃO & $-0,01969$ & $-0,02728$ & $-0,04100$ \\
\hline TAEE11 & NÃO & $-0,01908$ & $-0,02436$ & $-0,02997$ \\
\hline MDIA3 & NÃO & $-0,01853$ & $-0,02007$ & $-0,02772$ \\
\hline LPSB3 & NÃO & $-0,01111$ & $-0,02668$ & $-0,03883$ \\
\hline
\end{tabular}


APÊNDICE H - VAR 2007 POR ORDEM DE VAR MÉDIO

\begin{tabular}{|c|c|c|c|c|}
\hline Empresa & PE/VC & VaR Mínimo & VaR Médio & VaR Máximo \\
\hline VIVR3 & SIM & $-0,03814$ & $-0,07721$ & $-0,24017$ \\
\hline PDGR3 & SIM & $-0,04572$ & $-0,05022$ & $-0,05447$ \\
\hline MRFG3 & NÃO & $-0,04231$ & $-0,04695$ & $-0,04945$ \\
\hline MRVE3 & SIM & $-0,02425$ & $-0,04570$ & $-0,08370$ \\
\hline JBSS3 & NÃO & $-0,03870$ & $-0,04338$ & $-0,04732$ \\
\hline SGPS3 & SIM & $-0,02239$ & $-0,04315$ & $-0,17003$ \\
\hline CRDE3 & NÃO & $-0,03715$ & $-0,04058$ & $-0,04637$ \\
\hline TRIS3 & NÃO & $-0,03379$ & $-0,03890$ & $-0,04320$ \\
\hline TEMP3 & SIM & $-0,03438$ & $-0,03741$ & $-0,03943$ \\
\hline SULA11 & NÃO & $-0,03037$ & $-0,03405$ & $-0,03923$ \\
\hline GSHP3 & NÃO & $-0,03244$ & $-0,03368$ & $-0,03531$ \\
\hline BICB4 & NÃO & $-0,02125$ & $-0,03341$ & $-0,06099$ \\
\hline TCSA3 & NÃO & $-0,02544$ & $-0,03281$ & $-0,03720$ \\
\hline BEEF3 & NÃO & $-0,02903$ & $-0,03249$ & $-0,03577$ \\
\hline BBRK3 & SIM & $-0,02844$ & $-0,03160$ & $-0,03552$ \\
\hline EVEN3 & SIM & $-0,02434$ & $-0,03133$ & $-0,06909$ \\
\hline BEMA3 & SIM & $-0,01420$ & $-0,03104$ & $-0,07860$ \\
\hline FRIO3 & NÃO & $-0,02594$ & $-0,03079$ & $-0,03630$ \\
\hline DAYC4 & NÃO & $-0,01947$ & $-0,03077$ & $-0,07256$ \\
\hline SFSA4 & NÃO & $-0,01415$ & $-0,03006$ & $-0,07431$ \\
\hline LOGN3 & NÃO & $-0,02577$ & $-0,02976$ & $-0,03805$ \\
\hline SLCE3 & NÃO & $-0,02820$ & $-0,02920$ & $-0,03055$ \\
\hline HBOR3 & NÃO & $-0,02741$ & $-0,02915$ & $-0,03128$ \\
\hline BVMF3 & NÃO & $-0,02720$ & $-0,02906$ & $-0,03075$ \\
\hline ABCB4 & NÃO & $-0,02538$ & $-0,02829$ & $-0,03359$ \\
\hline RDNI3 & NÃO & $-0,02384$ & $-0,02826$ & $-0,03419$ \\
\hline BRML3 & SIM & $-0,02529$ & $-0,02727$ & $-0,03031$ \\
\hline KROT3 & NÃO & $-0,02004$ & $-0,02678$ & $-0,05046$ \\
\hline TPIS3 & NÃO & $-0,02295$ & $-0,02668$ & $-0,04078$ \\
\hline CREM3 & SIM & $-0,02261$ & $-0,02647$ & $-0,07614$ \\
\hline SMTO3 & NÃO & $-0,02483$ & $-0,02618$ & $-0,02736$ \\
\hline AMAR3 & NÃO & $-0,01456$ & $-0,02595$ & $-0,04594$ \\
\hline PINE4 & NÃO & $-0,01828$ & $-0,02529$ & $-0,06708$ \\
\hline ESTC3 & NÃO & $-0,02084$ & $-0,02387$ & $-0,03214$ \\
\hline
\end{tabular}




\begin{tabular}{|l|l|l|l|l|}
\hline \multicolumn{1}{|c|}{ Empresa } & \multicolumn{1}{c|}{ PE/VC } & \multicolumn{1}{c|}{ VaR Mínimo } & \multicolumn{1}{c|}{ VaR Médio } & \multicolumn{1}{c|}{ VaR Máximo } \\
\hline BHGR3 & NÃO & $-0,02111$ & $-0,02348$ & $-0,02717$ \\
\hline CZLT33 & NÃO & $-0,02071$ & $-0,02323$ & $-0,03633$ \\
\hline IGTA3 & NÃO & $-0,01523$ & $-0,02311$ & $-0,03485$ \\
\hline EZTC3 & NÃO & $-0,01572$ & $-0,02298$ & $-0,03996$ \\
\hline PRVI3 & SIM & $-0,01381$ & $-0,02293$ & $-0,07413$ \\
\hline WSON33 & NÃO & $-0,02038$ & $-0,02271$ & $-0,02495$ \\
\hline IDVL4 & NÃO & $-0,01315$ & $-0,02146$ & $-0,05589$ \\
\hline PRBC4 & NÃO & $-0,02002$ & $-0,02132$ & $-0,02289$ \\
\hline MULT3 & NÃO & $-0,01816$ & $-0,02121$ & $-0,02578$ \\
\hline JHSF3 & NÃO & - & - & - \\
\hline TGMA3 & NÃO & - & - & - \\
\hline ENEV3 & NÃO & - & - & - \\
\hline
\end{tabular}


APÊNDICE I - VAR 2007 POR ORDEM DE VAR MÁXIMO

\begin{tabular}{|c|c|c|c|c|}
\hline Empresa & PE/VC & VaR Mínimo & VaR Médio & VaR Máximo \\
\hline VIVR3 & SIM & $-0,03814$ & $-0,07721$ & $-0,24017$ \\
\hline SGPS3 & SIM & $-0,02239$ & $-0,04315$ & $-0,17003$ \\
\hline MRVE3 & SIM & $-0,02425$ & $-0,04570$ & $-0,08370$ \\
\hline BEMA3 & SIM & $-0,01420$ & $-0,03104$ & $-0,07860$ \\
\hline CREM3 & SIM & $-0,02261$ & $-0,02647$ & $-0,07614$ \\
\hline SFSA4 & NÃO & $-0,01415$ & $-0,03006$ & $-0,07431$ \\
\hline PRVI3 & SIM & $-0,01381$ & $-0,02293$ & $-0,07413$ \\
\hline DAYC4 & NÃO & $-0,01947$ & $-0,03077$ & $-0,07256$ \\
\hline EVEN3 & SIM & $-0,02434$ & $-0,03133$ & $-0,06909$ \\
\hline PINE4 & NÃO & $-0,01828$ & $-0,02529$ & $-0,06708$ \\
\hline BICB4 & NÃO & $-0,02125$ & $-0,03341$ & $-0,06099$ \\
\hline IDVL4 & NÃO & $-0,01315$ & $-0,02146$ & $-0,05589$ \\
\hline PDGR3 & SIM & $-0,04572$ & $-0,05022$ & $-0,05447$ \\
\hline KROT3 & NÃO & $-0,02004$ & $-0,02678$ & $-0,05046$ \\
\hline MRFG3 & NÃO & $-0,04231$ & $-0,04695$ & $-0,04945$ \\
\hline JBSS3 & NÃO & $-0,03870$ & $-0,04338$ & $-0,04732$ \\
\hline CRDE3 & NÃO & $-0,03715$ & $-0,04058$ & $-0,04637$ \\
\hline AMAR3 & NÃO & $-0,01456$ & $-0,02595$ & $-0,04594$ \\
\hline TRIS3 & NÃO & $-0,03379$ & $-0,03890$ & $-0,04320$ \\
\hline TPIS3 & NÃO & $-0,02295$ & $-0,02668$ & $-0,04078$ \\
\hline EZTC3 & NÃO & $-0,01572$ & $-0,02298$ & $-0,03996$ \\
\hline TEMP3 & SIM & $-0,03438$ & $-0,03741$ & $-0,03943$ \\
\hline SULA11 & NÃO & $-0,03037$ & $-0,03405$ & $-0,03923$ \\
\hline LOGN3 & NÃO & $-0,02577$ & $-0,02976$ & $-0,03805$ \\
\hline TCSA3 & NÃO & $-0,02544$ & $-0,03281$ & $-0,03720$ \\
\hline CZLT33 & NÃO & $-0,02071$ & $-0,02323$ & $-0,03633$ \\
\hline FRIO3 & NÃO & $-0,02594$ & $-0,03079$ & $-0,03630$ \\
\hline BEEF3 & NÃO & $-0,02903$ & $-0,03249$ & $-0,03577$ \\
\hline BBRK3 & SIM & $-0,02844$ & $-0,03160$ & $-0,03552$ \\
\hline GSHP3 & NÃO & $-0,03244$ & $-0,03368$ & $-0,03531$ \\
\hline IGTA3 & NÃO & $-0,01523$ & $-0,02311$ & $-0,03485$ \\
\hline RDNI3 & NÃO & $-0,02384$ & $-0,02826$ & $-0,03419$ \\
\hline ABCB4 & NÃO & $-0,02538$ & $-0,02829$ & $-0,03359$ \\
\hline ESTC3 & NÃO & $-0,02084$ & $-0,02387$ & $-0,03214$ \\
\hline
\end{tabular}




\begin{tabular}{|c|c|r|r|r|}
\hline Empresa & PE/VC & VaR Mínimo & VaR Médio & \multicolumn{1}{c|}{ VaR Máximo } \\
\hline HBOR3 & NÃO & $-0,02741$ & $-0,02915$ & $-0,03128$ \\
\hline BVMF3 & NÃO & $-0,02720$ & $-0,02906$ & $-0,03075$ \\
\hline SLCE3 & NÃO & $-0,02820$ & $-0,02920$ & $-0,03055$ \\
\hline BRML3 & SIM & $-0,02529$ & $-0,02727$ & $-0,03031$ \\
\hline SMTO3 & NÃO & $-0,02483$ & $-0,02618$ & $-0,02736$ \\
\hline BHGR3 & NÃO & $-0,02111$ & $-0,02348$ & $-0,02717$ \\
\hline MULT3 & NÃO & $-0,01816$ & $-0,02121$ & $-0,02578$ \\
\hline WSON33 & NÃO & $-0,02038$ & $-0,02271$ & $-0,02495$ \\
\hline PRBC4 & NÃO & $-0,02002$ & $-0,02132$ & $-0,02289$ \\
\hline JHSF3 & NÃO & - & - & - \\
\hline TGMA3 & NÃO & - & - & - \\
\hline ENEV3 & NÃO & - & - & - \\
\hline
\end{tabular}




\section{APÊNDICE J - VAR 2007 POR ORDEM DE VAR MÍNIMO}

\begin{tabular}{|c|c|c|c|c|}
\hline Empresa & PE/VC & VaR Mínimo & VaR Médio & VaR Máximo \\
\hline PDGR3 & SIM & $-0,04572$ & $-0,05022$ & $-0,05447$ \\
\hline MRFG3 & NÃO & $-0,04231$ & $-0,04695$ & $-0,04945$ \\
\hline JBSS3 & NÃO & $-0,03870$ & $-0,04338$ & $-0,04732$ \\
\hline VIVR3 & SIM & $-0,03814$ & $-0,07721$ & $-0,24017$ \\
\hline CRDE3 & NÃO & $-0,03715$ & $-0,04058$ & $-0,04637$ \\
\hline TEMP3 & SIM & $-0,03438$ & $-0,03741$ & $-0,03943$ \\
\hline TRIS3 & NÃO & $-0,03379$ & $-0,03890$ & $-0,04320$ \\
\hline GSHP3 & NÃO & $-0,03244$ & $-0,03368$ & $-0,03531$ \\
\hline SULA11 & NÃO & $-0,03037$ & $-0,03405$ & $-0,03923$ \\
\hline BEEF3 & NÃO & $-0,02903$ & $-0,03249$ & $-0,03577$ \\
\hline BBRK3 & SIM & $-0,02844$ & $-0,03160$ & $-0,03552$ \\
\hline SLCE3 & NÃO & $-0,02820$ & $-0,02920$ & $-0,03055$ \\
\hline HBOR3 & NÃO & $-0,02741$ & $-0,02915$ & $-0,03128$ \\
\hline BVMF3 & NÃO & $-0,02720$ & $-0,02906$ & $-0,03075$ \\
\hline FRIO3 & NÃO & $-0,02594$ & $-0,03079$ & $-0,03630$ \\
\hline LOGN3 & NÃO & $-0,02577$ & $-0,02976$ & $-0,03805$ \\
\hline TCSA3 & NÃO & $-0,02544$ & $-0,03281$ & $-0,03720$ \\
\hline ABCB4 & NÃO & $-0,02538$ & $-0,02829$ & $-0,03359$ \\
\hline BRML3 & SIM & $-0,02529$ & $-0,02727$ & $-0,03031$ \\
\hline SMTO3 & NÃO & $-0,02483$ & $-0,02618$ & $-0,02736$ \\
\hline EVEN3 & SIM & $-0,02434$ & $-0,03133$ & $-0,06909$ \\
\hline MRVE3 & SIM & $-0,02425$ & $-0,04570$ & $-0,08370$ \\
\hline RDNI3 & NÃO & $-0,02384$ & $-0,02826$ & $-0,03419$ \\
\hline TPIS3 & NÃO & $-0,02295$ & $-0,02668$ & $-0,04078$ \\
\hline CREM3 & SIM & $-0,02261$ & $-0,02647$ & $-0,07614$ \\
\hline SGPS3 & SIM & $-0,02239$ & $-0,04315$ & $-0,17003$ \\
\hline BICB4 & NÃO & $-0,02125$ & $-0,03341$ & $-0,06099$ \\
\hline BHGR3 & NÃO & $-0,02111$ & $-0,02348$ & $-0,02717$ \\
\hline ESTC3 & NÃO & $-0,02084$ & $-0,02387$ & $-0,03214$ \\
\hline CZLT33 & NÃO & $-0,02071$ & $-0,02323$ & $-0,03633$ \\
\hline WSON33 & NÃO & $-0,02038$ & $-0,02271$ & $-0,02495$ \\
\hline KROT3 & NÃO & $-0,02004$ & $-0,02678$ & $-0,05046$ \\
\hline PRBC4 & NÃO & $-0,02002$ & $-0,02132$ & $-0,02289$ \\
\hline DAYC4 & NÃO & $-0,01947$ & $-0,03077$ & $-0,07256$ \\
\hline PINE4 & NÃO & $-0,01828$ & $-0,02529$ & $-0,06708$ \\
\hline
\end{tabular}




\begin{tabular}{|c|c|r|r|r|}
\hline Empresa & PE/VC & VaR Mínimo & \multicolumn{1}{c|}{ VaR Médio } & \multicolumn{1}{c|}{ VaR Máximo } \\
\hline MULT3 & NÃO & $-0,01816$ & $-0,02121$ & $-0,02578$ \\
\hline EZTC3 & NÃO & $-0,01572$ & $-0,02298$ & $-0,03996$ \\
\hline IGTA3 & NÃO & $-0,01523$ & $-0,02311$ & $-0,03485$ \\
\hline AMAR3 & NÃO & $-0,01456$ & $-0,02595$ & $-0,04594$ \\
\hline BEMA3 & SIM & $-0,01420$ & $-0,03104$ & $-0,07860$ \\
\hline SFSA4 & NÃO & $-0,01415$ & $-0,03006$ & $-0,07431$ \\
\hline PRVI3 & SIM & $-0,01381$ & $-0,02293$ & $-0,07413$ \\
\hline IDVL4 & NÃO & $-0,01315$ & $-0,02146$ & $-0,05589$ \\
\hline JHSF3 & NÃO & - & - & - \\
\hline TGMA3 & NÃO & - & - & - \\
\hline ENEV3 & NÃO & - & - & - \\
\hline
\end{tabular}


Júlio Pereira de Araújo, Marcos Roberto Gois de Oliveira

APÊNDICE L - VAR 2009 POR ORDEM DE VAR MÉDIO

\begin{tabular}{|c|c|r|r|r|}
\hline Empresa & PE/VC & VaR Mínimo & \multicolumn{1}{c|}{ VaR Médio } & \multicolumn{1}{c|}{ VaR Máximo } \\
\hline DIRR3 & SIM & $-0,01321$ & $-0,02811$ & $-0,04660$ \\
\hline CTIP3 & SIM & $-0,02138$ & $-0,02515$ & $-0,02696$ \\
\hline CIEL3 & NÃO & $-0,01874$ & $-0,02411$ & $-0,02719$ \\
\hline FLRY3 & NÃO & $-0,01946$ & $-0,02251$ & $-0,02410$ \\
\hline
\end{tabular}




\section{APÊNDICE M - VAR 2009 POR ORDEM DE VAR MÁXIMO}

\begin{tabular}{|c|c|r|r|r|}
\hline Empresa & PE/VC & VaR Mínimo & \multicolumn{1}{c|}{ VaR Médio } & \multicolumn{1}{c|}{ VaR Máximo } \\
\hline DIRR3 & SIM & $-0,01321$ & $-0,02811$ & $-0,04660$ \\
\hline CIEL3 & NÃO & $-0,01874$ & $-0,02411$ & $-0,02719$ \\
\hline CTIP3 & SIM & $-0,02138$ & $-0,02515$ & $-0,02696$ \\
\hline FLRY3 & NÃO & $-0,01946$ & $-0,02251$ & $-0,02410$ \\
\hline
\end{tabular}


Júlio Pereira de Araújo, Marcos Roberto Gois de Oliveira

\section{APÊNDICE N - VAR 2009 POR ORDEM DE VAR MÍNIMO}

\begin{tabular}{|c|c|r|r|r|}
\hline Empresa & PE/VC & \multicolumn{1}{|c|}{ VaR Mínimo } & \multicolumn{1}{c|}{ VaR Médio } & \multicolumn{1}{c|}{ VaR Máximo } \\
\hline CTIP3 & SIM & $-0,02138$ & $-0,02515$ & $-0,02696$ \\
\hline FLRY3 & NÃO & $-0,01946$ & $-0,02251$ & $-0,02410$ \\
\hline CIEL3 & NÃO & $-0,01874$ & $-0,02411$ & $-0,02719$ \\
\hline DIRR3 & SIM & $-0,01321$ & $-0,02811$ & $-0,04660$ \\
\hline
\end{tabular}




\section{APÊNDICE O - VAR 2010 POR ORDEM DE VAR MÉDIO}

\begin{tabular}{|c|c|r|r|r|}
\hline Empresa & PE/VC & VaR Mínimo & VaR Médio & \multicolumn{1}{c|}{ VaR Máximo } \\
\hline HRTP3 & SIM & $-0,07544$ & $-0,07983$ & $-0,08717$ \\
\hline MPLU3 & NÃO & $-0,02970$ & $-0,03337$ & $-0,03621$ \\
\hline RNEW11 & SIM & $-0,02606$ & $-0,02765$ & $-0,03073$ \\
\hline BRIN3 & SIM & $-0,02392$ & $-0,02697$ & $-0,02854$ \\
\hline MILS3 & SIM & $-0,02496$ & $-0,02629$ & $-0,02793$ \\
\hline BRPR3 & SIM & $-0,02494$ & $-0,02615$ & $-0,02755$ \\
\hline ALSC3 & NÃO & $-0,02059$ & $-0,02239$ & $-0,02434$ \\
\hline ECOR3 & NÃO & $-0,01353$ & $-0,01921$ & $-0,03980$ \\
\hline OSXB3 & NÃO & - & - & - \\
\hline
\end{tabular}




\section{APÊNDICE P - VAR 2010 POR ORDEM DE VAR MÁXIMO}

\begin{tabular}{|c|c|r|r|r|}
\hline Empresa & PE/VC & VaR Mínimo & VaR Médio & VaR Máximo \\
\hline HRTP3 & SIM & $-0,07544$ & $-0,07983$ & $-0,08717$ \\
\hline ECOR3 & NÃO & $-0,01353$ & $-0,01921$ & $-0,03980$ \\
\hline MPLU3 & NÃO & $-0,02970$ & $-0,03337$ & $-0,03621$ \\
\hline RNEW11 & SIM & $-0,02606$ & $-0,02765$ & $-0,03073$ \\
\hline BRIN3 & SIM & $-0,02392$ & $-0,02697$ & $-0,02854$ \\
\hline MILS3 & SIM & $-0,02496$ & $-0,02629$ & $-0,02793$ \\
\hline BRPR3 & SIM & $-0,02494$ & $-0,02615$ & $-0,02755$ \\
\hline ALSC3 & NÃO & $-0,02059$ & $-0,02239$ & $-0,02434$ \\
\hline OSXB3 & NÃO & - & & - \\
\hline
\end{tabular}




\section{APÊNDICE Q - VAR 2010 POR ORDEM DE VAR MÍNIMO}

\begin{tabular}{|c|c|r|r|r|}
\hline Empresa & PE/VC & VaR Mínimo & VaR Médio & \multicolumn{1}{c|}{ VaR Máximo } \\
\hline HRTP3 & SIM & $-0,07544$ & $-0,07983$ & $-0,08717$ \\
\hline MPLU3 & NÃO & $-0,02970$ & $-0,03337$ & $-0,03621$ \\
\hline RNEW11 & SIM & $-0,02606$ & $-0,02765$ & $-0,03073$ \\
\hline MILS3 & SIM & $-0,02496$ & $-0,02629$ & $-0,02793$ \\
\hline BRPR3 & SIM & $-0,02494$ & $-0,02615$ & $-0,02755$ \\
\hline BRIN3 & SIM & $-0,02392$ & $-0,02697$ & $-0,02854$ \\
\hline ALSC3 & NÃO & $-0,02059$ & $-0,02239$ & $-0,02434$ \\
\hline ECOR3 & NÃO & $-0,01353$ & $-0,01921$ & $-0,03980$ \\
\hline OSXB3 & NÃO & - & - & - \\
\hline
\end{tabular}


